\title{
Proteomics Readjustment of the Yarrowia lipolytica Yeast in Response to Increased Temperature and Alkaline Stress
}

\author{
Varvara Y. Sekova (D, Leonid I. Kovalyov, Marina A. Kovalyova, Natalya N. Gessler, Maria A. Danilova, \\ Elena P. Isakova * and Yulia I. Deryabina
}

check for updates

Citation: Sekova, V.Y.; Kovalyov, L.I.; Kovalyova, M.A.; Gessler, N.N.; Danilova, M.A.; Isakova, E.P.; Deryabina, Y.I. Proteomics Readjustment of the Yarrowia lipolytica Yeast in Response to Increased Temperature and Alkaline Stress. Microorganisms 2021, 9, 2619. https://doi.org/10.3390/ microorganisms 9122619

Academic Editor: Benedetta Turchetti

Received: 9 November 2021

Accepted: 14 December 2021

Published: 18 December 2021

Publisher's Note: MDPI stays neutral with regard to jurisdictional claims in published maps and institutional affiliations.

Copyright: (c) 2021 by the authors. Licensee MDPI, Basel, Switzerland. This article is an open access article distributed under the terms and conditions of the Creative Commons Attribution (CC BY) license (https:/ / creativecommons.org/licenses/by/ $4.0 /)$.
A.N. Bach Institute of Biochemistry, Research Center of Biotechnology of the Russian Academy of Sciences, Leninsky Ave. 33/2, 119071 Moscow, Russia; beauveria606@gmail.com (V.Y.S.); kovalyov@inbi.ras.ru (L.I.K.); M1968@mail.ru (M.A.K.); gessler51@mail.ru (N.N.G.); ms.maria.danilova@gmail.com (M.A.D.); yul_der@mail.ru (Y.I.D.)

* Correspondence: elen_iss@mail.ru; Tel.: +7-(495)-954-4008

Abstract: Yeasts cope with a wide range of environmental challenges using different adaptive mechanisms. They can prosper at extreme ambient $\mathrm{pH}$ and high temperatures; however, their adaptation mechanisms have not been entirely investigated. Previously, we showed the pivotal role and flexibility of the sugar and lipid composition of Yarrowia lipolytica W 29 upon adaptation to unfavorable conditions. In this study, we showed that extreme $\mathrm{pH}$ provoked significant changes in the cell wall proteins expression, with an increase in both the chaperones of heat shock protein HSP60 and some other proteins with chaperone functions. The mitochondria activity changes inducing the VDAC and malate dehydrogenase played an essential role in the adaptation, as did the altered carbohydrate metabolism, promoting its shift towards the pyruvate formation rather than gluconeogenesis. The elevated temperature led to changes in the cell wall proteins and chaperones, the induced expression of the proteins involved in the cell structural organization, ribosomal proteins, and the enzymes of formaldehyde degradation. Moreover, the readjustment of the protein composition and amount under combined stress indicated the promotion of catabolic processes related to scavenging the damaged proteins and lipids. Under all of the stress conditions studied, the process of folding, stress resistance, redox adaptation, and oxidative phosphorylation were the dominant pathways. The combined chronic alkaline and heat stress ( $\left.\mathrm{pH} 9.0,38^{\circ} \mathrm{C}\right)$ led to cross-adaptation, which caused "switching" over the traditional metabolism to the adaptation to the most damaging stress factor, namely the increased temperature.

Keywords: yeast; heat shock; extreme ambient $\mathrm{pH}$; combined stress; proteomic readjustments

\section{Introduction}

The ability of a living organism to prosper under different kinds of stress is associated with the changes in the gene expression profile followed by significant readjustment at the molecular and biochemical levels. Some abiotic environmental factors, namely extreme ambient $\mathrm{pH}$, high temperatures, and osmolarity, lead to the most remarkable influence on the growth and development of yeast cells. The adaptation to these conditions mainly includes the increased synthesis of some stress proteins and the essential rearrangement of cell metabolism. In addition, it leads to compositional changes in membrane lipids and the accumulation of various osmolytes and protective agents in the cytosol [1]. The extremophile Yarrowia lipolytica is a unique yeast which thrives in a wide range of environmental challenges such as ambient $\mathrm{pH}$ from 2.5 up to 9.5 [2,3], high salinity, dry or hydrophobic substrates [Liu et al., 2015], and elevated temperatures up to $38^{\circ} \mathrm{C}[4]$.

A yeast's adaptation to various stresses includes some metabolic pathways, namely changes in fatty acid synthesis, their unsaturation degree, modification of membrane phospholipid components, some alterations in the cAMP levels, the mitochondrial activity, 
and ATP synthesis [5]. The exclusive mechanism of a general response to the stress in a yeast is supposed to protect a cell against harmful environmental challenges [6].

Nevertheless, metabolic readjustment due to the changes in the cell proteomic composition is a keystone of the adaptation to any stress. In the paper by [7], the authors showed that the proteome of Y. lipolytica yeast WSH-Z06 significantly changed under acid stress during the production of $\alpha$-ketoglutaric acid. The proteins maintaining intracellular $\mathrm{pH}$ homeostasis, which greatly increased at acidic $\mathrm{pH}$, were divided into several groups according to their functions in the cells. The authors speculated that the ATP synthesis activates due to membrane hyper-polarization upon cytoplasm acidulation. It causes an increase in ROS generation, and the cells need antioxidant components and chaperones to protect the cell against ROS. To induce metabolite exchange between the cytosol and mitochondria, the VDAC level in the cells increases. The Y. lipolytica proteome under alkaline stress compared to that under normal conditions was studied before [8]. The authors showed that the level of some mitochondrial proteins, namely $\alpha$-ketoglutarate dehydrogenase, malate dehydrogenase, some outer membrane proteins (porin VDAC), and the respiratory chain components, notably increased in the cells under alkaline conditions ( $\mathrm{pH}$ 8.5). Moreover, the level of the cytoprotective proteins, in particular, $\mathrm{Cu} / \mathrm{Zn}$-superoxide dismutase (SOD), rose. However, the authors failed to detect an increase in the $\mathrm{Na}^{+}$-dependent ATPase level in the cells, which would presumably provide the phosphate transport upon the cytoplasmic membrane depolarization. This was shown in the paper by [9], where the response of the Y. lipolytica CICC 1675 proteome to osmotic stress at a high $\mathrm{NaCl}$ concentration (up to $70 \mathrm{~g} / \mathrm{L}$ ) was under investigation. Among the 55 up-regulated proteins during osmotic stress, TCA enzymes, respiratory chain components, antioxidant enzymes, heat shock proteins, and carbohydrate metabolism enzymes responsible for the osmolytes synthesis were revealed.

Several studies indicating the general response to stress in the $Y$. lipolytica yeast have previously been published [10]. They showed cross-adaptation between some stressors such as heat shock, osmotic stress, ethanol, and induced oxidative stress. The authors found the ROS scavenging enzymes such as SOD, catalase, alternative mitochondrial oxidase, and glutathione reductase to be the key components of the general response.

In our recent studies, we researched the adaptation of the $Y$. lipolytica yeast to $\mathrm{pH}$ and heat stresses at the level of the glycom and lipidome, as well as the redox status of the cells [4]. The increased growth temperature was recorded to affect the carbohydrate and lipid metabolism more than the alkaline conditions did. Thus, mannitol was the dominating soluble carbohydrate of the cytosol upon the cultivation at $29^{\circ} \mathrm{C}$. However, at the increased temperature of $38^{\circ} \mathrm{C}$, mannitol was substituted by trehalose, possessing a thermo-protective effect [4].

In the present study, we show the adaptive proteomic readjustment of the Y. lipolytica yeast under thermal, alkaline, and combined stresses to identify the metabolic pathways involved in the adaptation of the cells.

\section{Methods and Materials}

\subsection{Yeast Strain and Growth Conditions}

Wild-type Yarrowia lipolytica W 29 from CIRM Levures collection (France) was used. The culture was raised in batches of $100 \mathrm{~mL}$ in glycerol (1\%)-containing medium of the following composition (g/L): $\mathrm{Mg}_{2} \mathrm{SO}_{4}-0.5,\left(\mathrm{NH}_{4}\right)_{2} \mathrm{SO}_{4}-0.3, \mathrm{KH}_{2} \mathrm{PO}_{4}-2.0, \mathrm{~K}_{2} \mathrm{HPO}_{4}-0.5, \mathrm{NaCl}-0.1$, $\left.\mathrm{CaCl}_{2}-0.05\right)$. Then, $2 \mathrm{M} \mathrm{KP}$ s stock buffer was prepared by dissolving $\mathrm{KH}_{2} \mathrm{PO}_{4}$ anhydrous (272 g/L, Amresco Cat No. 0781), pH adjusted with $2 \mathrm{M} \mathrm{K}_{2} \mathrm{HPO}_{4}$ to 6.0. Furthermore, $2 \mathrm{M} \mathrm{KP} \mathrm{P}_{\mathrm{i}}$ stock buffer was prepared by dissolving $\mathrm{K}_{2} \mathrm{HPO}_{4}$ anhydrous $(342 \mathrm{~g} / \mathrm{L}$, Amresco Cat No. 0705), and the $\mathrm{pH}$ was adjusted with $2 \mathrm{M} \mathrm{KH}_{2} \mathrm{PO}_{4}$ to 9.0. Both $\mathrm{KP}_{\mathrm{i}}$ buffers were sterilized by autoclaving and added to sterilize the culture medium (ratio 1:40) just before inoculation. The yeast was cultivated at two ambient $\mathrm{pH}$ values of 5.5 and 9.0 and two temperatures of 29 and $38{ }^{\circ} \mathrm{C}$ on a rotary shaker at 150 r.p.m, as described by [4]. Absorbance (A) was assessed in cell suspension at the wavelength of $590 \mathrm{~nm}\left(\mathrm{~A}_{590}\right)$ using a 
Specol-11 spectrophotometer (Carl Zeiss, Oberkochen, Germany). The yeast was raised in the stationary growth phase.

\subsection{Sampling}

The biomass was harvested by centrifugation at $4000 \times g$ for $10 \mathrm{~min}$. The cells were washed twice with ice-cold deionized water and eventually pelleted. To prepare protein extracts, $100 \mathrm{mg}$ of the cell pellet was transferred to a vial containing $2 \mathrm{~mL}$ of lysis buffer (9 M urea, 5\% $\beta$-mercaptoethanol, 2\% Triton X-100, and 2\% ampholytes, $\mathrm{pH} 3.5-10$ (Sigma, Sigma-Aldrich, St. Louis, MO, USA) and thoroughly suspended. The sample was either immediately heated in a boiling bath for 3-5 min or placed on ice and sonicated in an ultrasonic desintegrator (MSE-Pharmacia, Stockholm, Sweeden) for 2 min (4 cycles, $30 \mathrm{~s}$ each). In both cases, the homogenate was clarified by centrifugation in a microfuge for $20 \mathrm{~min}$ at maximum speed. The pellet was discarded, and $100 \mu \mathrm{L}$ of the clear supernatant was used for isoelectrofocusing (IEF).

\subsection{Proteomic Analysis}

The preparation of protein extracts, their fractionation by $\mathrm{O}^{\prime}$ Farrell two-dimensional electrophoresis (2DE) with own modifications, and analysis of electrophoregrams were performed as described before [11,12]. At least three 2DE electrophoregrams were tested for each sample. The kits of highly purified recombinant proteins SM0661 (10-200 kDa), and SM0671 (10-170 kDa) (Fermentas, Waltham, MA, USA) were used as molecular-weight standards to calculate sample molecular weights. To visualize proteins, the polyacrylamide gel slabs were stained with Coomassie Blue R22 250 and then with silver nitrate according to well-described methods [13] and modified by the addition of $0.8 \%$ acetic acid to sodium thiosulfate. The stained gels were documented by scanning on an Epson Expression 1680 scanner (Epson, Suwa, Nagano, Japan), and densitometry was carried out using the Melanie software (GeneBio, Genève, Switzerland) according to the producer's protocol. Theoretical values of $\mathrm{M}$ and $\mathrm{pI}$ were calculated using the "pI/ $\mathrm{Mw}^{\prime \prime}$ software in open access at the ExPASy Proteomics Server (http:/ / cn.expasy.org; accessed date: 10 October 2021) and data on amino acid sequences of corresponding proteins in SwissProt database considering the evidence for post-translational removal of signal sequences.

\subsection{Protein Identification by Mass Spectrometry}

The fractions chosen for identification were cut out from the 2DE gels and the proteins were hydrolyzed by trypsin. The extracted tryptic peptides were assayed using MALDITOF MS as described previously with some modifications [14]. The sample $(0.5 \mu \mathrm{L})$ was mixed with the same volume of $20 \%$ acetonitril solution containing $0.1 \%$ of trifluoroacetic acid and $20 \mathrm{mg} / \mathrm{mL}$ of 2, 5-dihydroxybenzoic acid (Sigma), and was air-dried. Mass spectra were acquired on Ultraflextreme MALDI-TOF mass spectrometers (Bruker, Bremen, Germany) with a UV laser (336 nm) in the 500-8000 Da range in the positive ion mode calibrated using reference trypsin autolysis peaks. During MS/MS analysis, the mass spectra of fragments were acquired on a Bruker Ultraflex MALDI-TOF mass spectrometer (Bruker, Bremen, Germany) in the positive ion mode. The results of protein identification were processed with Mascot software (FlexControl 3.3, FlexAnalisis 3.3 uBiotools 3.2), Peptide Fingerprint option (Matrix Science, Boston, MA, USA), with an accuracy of mass measurement $\mathrm{MH}+$ of $0.01 \%$ (with a possibility to modify cysteines by acrylamide and methionine oxidation).

\subsection{Statistical and Bioinformatics Analysis}

The data presented are the average results of at least $3-5$ replicates with a standard error of less than $5 \%$. Analysis of variance was performed using Primer of Biostatistics v. 4.03 software. Significant differences between calculated values were evaluated using a paired $t$-test at the $5 \%$ level of probability. 
The molecular weights of protein fractions of two-dimensional electrophoresis were assayed according to their electrophoretic mobility in the second direction comparing them to the standard proteins-markers $[10,15,16]$. The results were confirmed and, in some cases, corrected according to the calibration curve made using a set of highly purified recombinant proteins with molecular weights between 10 and 200 kDa (Fermentas, Waltham, MA, USA) [17].

For the analysis of protein-protein interactions, differentially expressed proteins were searched against the STRING database (Search Tool for the Retrieval of Interacting Genes/Protein, http://string-db.org/; accessed on 26 October 2021) with the highest confidence score (score $>0.9$ ). Only the interaction network with at least three proteins was shown, and the unconnected proteins or clusters with two proteins were not presented.

The measurements were carried out on the equipment of the Shared-Access Equipment Centre "Industrial Biotechnology" of Federal Research Center "Fundamentals of Biotechnology" Russian Academy of Sciences.

\section{Results and Discussion}

In this study, we compared the protein expression profile of the Y. lipolytica yeast cultivated at two ambient $\mathrm{pH}$ values (normal 5.5 and alkaline 9.0) and two growth temperatures (optimal, $29^{\circ} \mathrm{C}$ and elevated, $38^{\circ} \mathrm{C}$ ) in various combinations. Previously, we showed that growth conditions of $\mathrm{pH} 5.5$ and a temperature of $29^{\circ} \mathrm{C}$ could be regarded as the normal ones, while the shift in ambient $\mathrm{pH}$ to the alkaline side (9.0) or the increase in the growth temperature up to $38^{\circ} \mathrm{C}$ are the stress conditions. Growth at both alkaline $\mathrm{pH}$ and increased temperature is considered as being under combined stress [4]. The cultures grown under different conditions were raised at the stationary growth phase, extracted as described in the Materials and Methods, and the extracts were separated by $\mathrm{O}^{\prime}$ Farrell two-dimensional protein electrophoresis. Then, the protein spots, which under different conditions significantly varied in their relative amount, were identified using MALDI-TOF mass spectrometry for the determination of differentially expressed proteins (DEPs). Sixtysix protein spots were successfully identified using mass spectrometry from the cells grown under different conditions. Comparative proteomics was used to evaluate the response of the yeast to the stress conditions. Figure 1 shows the results of their comparison, and the citation to the database is presented in Figure S1. Table S1 presents the full protein list.

Six unique proteins were revealed in normal conditions (Figures 1 and S2B). Among them, there is one protein of oxidative phosphorylation, the $\alpha$-subunit of ATP synthase (YALI0F03179p); two structural proteins, mannoprotein of the cell wall Pir1 (YALI0B20306p) and profilin (YALI0B07183p), as well as thiol-specific peroxidase (YALI0A19426p) required to maintain cell redox homeostasis (Table 1). This set of proteins is associated with active cell growth and division (Figure S2). In total, we identified 51 expression proteins showing the most altered abundance in the normal and different stress conditions. Figure 1 demonstrates the experimental results of 2-DE gels. 


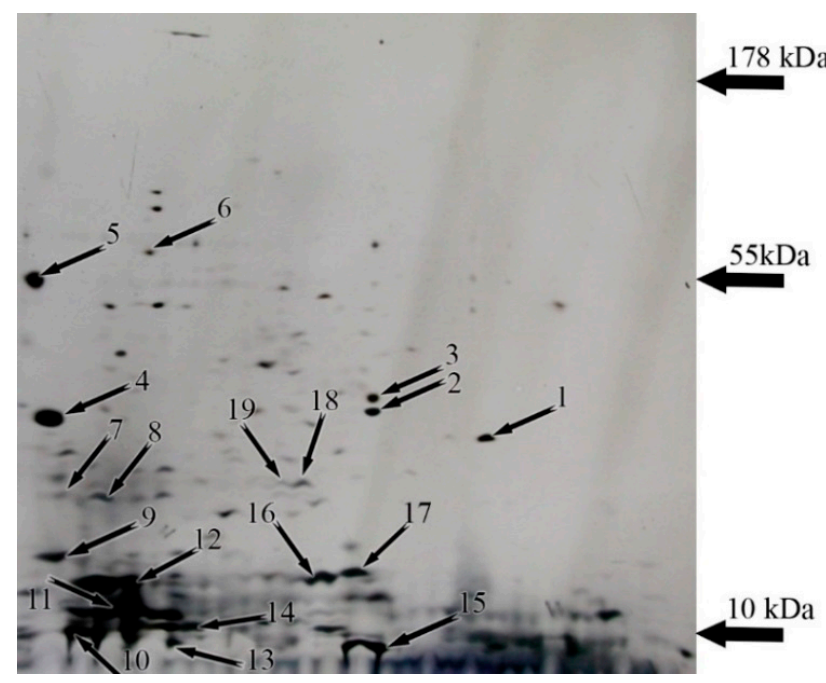

(A)

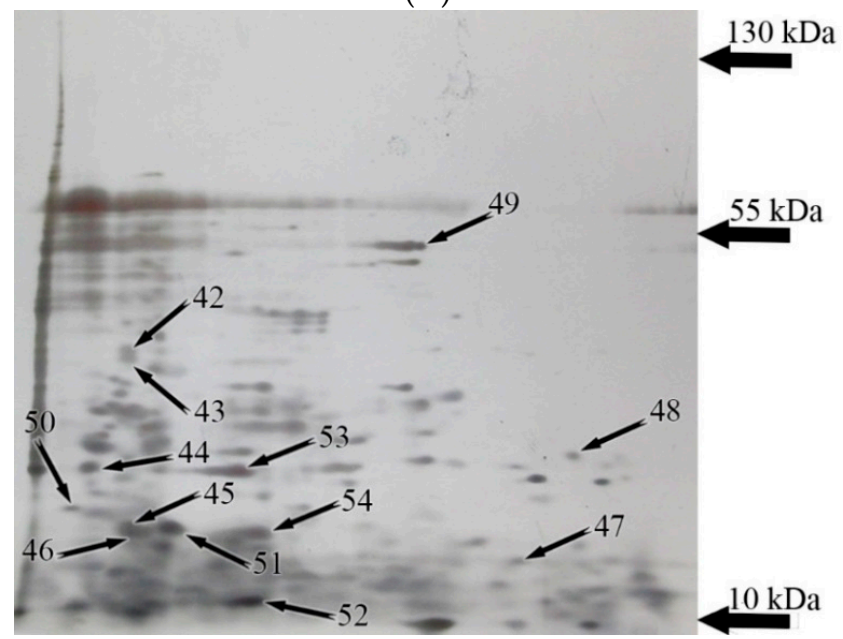

(C)

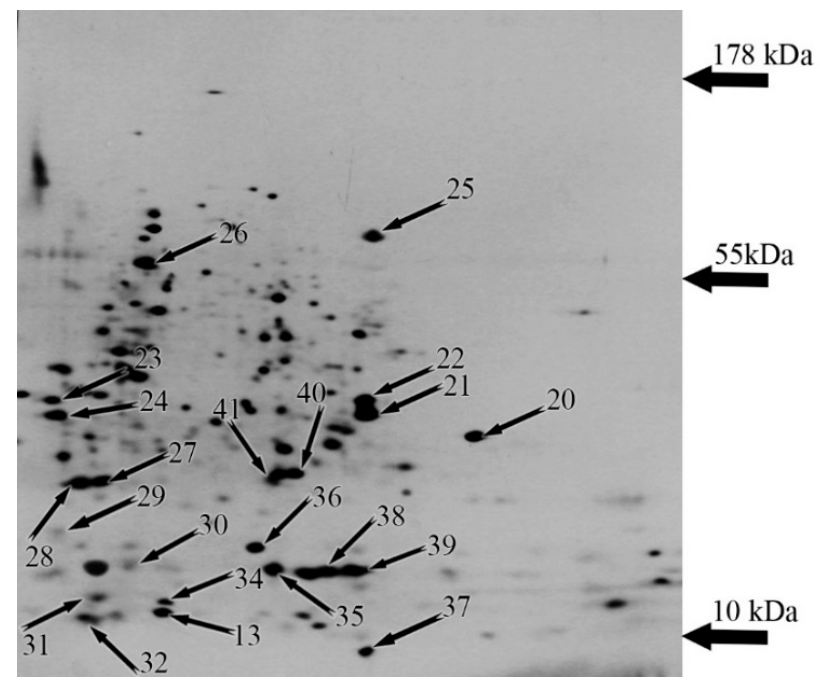

(B)

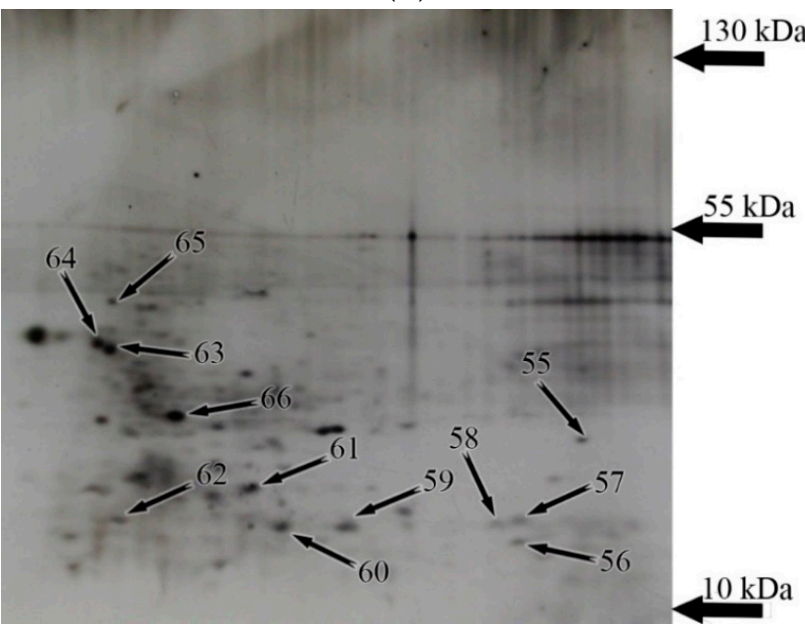

(D)

Figure 1. The 2-DE maps of the $Y$. lipolytica cells prepared with linear wide-range immobilized $\mathrm{pH}$ gradients ( $\mathrm{pH} 3-10$, $17 \mathrm{~cm}$, BioRad, Hercules, CA, USA) in the first dimension and on 12\% SDS-PAGE for the second dimension. Proteins were stained with colloidal Coomassie blue G-250. Labeled by small arrows spots indicate the proteins with the expression changed under various conditions. The conditions were: (A) normal; (B) alkaline stress; (C) heat stress; (D) combined stress. All the identified protein spots are numbered according to Table S1. Thick arrows are the markers of molecular mass.

Table 1. The expressed proteins identified in the 2-DE map of the Y. lipolytica cells under normal conditions.

\begin{tabular}{|c|c|c|c|c|c|}
\hline $\begin{array}{l}\text { Spot } \\
\text { Number }\end{array}$ & Protein Name & $\begin{array}{l}\text { NCBI or } \\
\text { UniProt ID }\end{array}$ & $\mathrm{S} / \mathrm{M} / \mathrm{C}^{*}$ & $\frac{\mathrm{M}_{\mathrm{M}} / \mathrm{pI}}{(\operatorname{expt.})^{* *}}$ & $\frac{\mathrm{M}_{\mathbf{M}} / \mathrm{pI}}{(\text { calc.) }}$ \\
\hline 5 & YALI0B20306p (Cell wall mannoprotein (Pir1)) & Q6CDY2 & $169 / 5 / 15$ & $50 / 4$ & $29.7 / 4.2$ \\
\hline 7 & YALI0F25289p (HSP70 heat shock protein) & Q6C0E9 & $96 / 9 / 14$ & $21 / 4.2$ & $70.4 / 4.6$ \\
\hline 9 & YALI0F03179p (ATP synthase subunit alpha) & Q6C326 & $149 / 16 / 16$ & $12 / 4.5$ & $58 / 4.8$ \\
\hline 13 & YALI0B07183p (Profilin) & WOTYP0 & $108 / 7 / 70$ & $9 / 5.8$ & $13.4 / 5.7$ \\
\hline 14 & $\begin{array}{l}\text { YALI0B10450p (Peptidyl-prolyl } \\
\text { cis-trans isomerase) }\end{array}$ & Q6CF41 & $215 / 12 / 85$ & $11 / 6.1$ & $11.6 / 6.0$ \\
\hline 19 & YALI0A19426p (Thiol-specific peroxidase) & Q6CGH1 & $118 / 7 / 42$ & $23 / 6.7$ & $24.6 / 5.9$ \\
\hline
\end{tabular}

*S/M/C-the Mascot Score is an indicator of conformity or "scorecard"; match peptides are the number of matched peptides; coverage is the percentage of the complete amino acid sequence of the protein using the identified peptides. ${ }^{* *} \mathrm{M}_{\mathrm{M}} / \mathrm{pI}$ (exp.) are the obtained estimates according to electrophoretic mobility in the $\mathrm{DE}, \mathrm{M}_{\mathrm{M}} / \mathrm{pI}$ (calc.) are the estimates made using the data on the amino acid sequence, taking into account signal peptide removal, but with no consideration of other post-synthetic modifications using the ExPASy Compute $\mathrm{pI} / \mathrm{M}_{\mathrm{w}}$ tool software. 


\subsection{Changes in the Yeast Proteomics at Alkaline Ambient $p H$}

Table 2 shows the results of mass spectrometric identification of the proteins from the cells grown under alkaline stress. Twelve original proteins were expressed in these conditions (Table 2, Figure S3): two proteins associated with the ubiquitination, namely the SCF subunit of the E3 ubiquitin ligase complex (zone 29, YALI0A10879p) and an endopeptidase activator (zone 24, YALI0B09339) (Figure S3B). Some other proteins expressed under alkaline $\mathrm{pH}$ are the members of the HSP family, namely small $20-\mathrm{kDa}$ HSP (zone 35, YALIOC03443p). Besides that, we could identify the $\beta$-subunit of the immature polypeptide-associated complex (zone 36, YALIOF08393p). NADPH dehydrogenase (zone 27, YALI0B07007p) involved in purine metabolism, bis (5'-adenosyl) triphosphatase (zone 30, YALI0E32736p), (zone 27, YALI0E19723p), and calcium binding protein 31 (YALIOE03388p) are also expressed in significant amounts in these conditions (Figures 1 and S3B, Table 2). Moreover, the uncharacterized protein of YALI0D00451p (zone 25) and a heat shock protein 70-related protein SSC1 mitochondria precursor (zone 41, YALI0C17347p) were among the proteins induced by alkaline stress. However, four proteins in the proteomic profile of the Y. lipolytica yeast grown under normal conditions disappeared, namely zone 5 (mannoprotein (Pir1, YALI0B20306p) and zone 19 (peroxiredoxin protein family, YALI0A19426p) (Figure 1).

Table 2. The list of induced proteins in response to alkaline stress in the Y. lipolytica yeast using mass spectrometry (MALDI-TOF MS and MS/MS) under alkaline conditions.

\begin{tabular}{|c|c|c|c|c|c|}
\hline $\begin{array}{l}\text { Spot } \\
\text { Number }\end{array}$ & Protein Name & $\begin{array}{l}\text { NCBI or } \\
\text { UniProt ID }\end{array}$ & $\mathrm{S} / \mathrm{M} / \mathrm{C}^{*}$ & $\underset{(\text { expt.) }}{\mathrm{M}_{\mathrm{M}} / \mathrm{pI}}$ & $\underset{\text { (calc.) }}{\mathrm{M}_{\mathrm{M}} / \mathrm{pI}}$ \\
\hline $24^{\ddagger}$ & $\begin{array}{l}\text { YALI0B09339p, endopeptidase activator activity } \\
\text { (281 a.o.) }\end{array}$ & Q6CF86 & $79 / 7 / 43$ & $31.0 / 4.6$ & $31.1 / 4.5$ \\
\hline 25 & $\begin{array}{c}\text { YALI0D00451p, Uncharacterized protein } \\
\text { (584 a.o.) }\end{array}$ & Q6CAS0 & $178 / 13 / 21$ & $57.0 / 7.7$ & $57.1 / 6.6$ \\
\hline $27 \ddagger$ & $\begin{array}{c}\text { YALI0B07007p, NAD(P)H dehydrogenase } \\
\text { (quinone) activity } \\
\text { (203 a.o.) }\end{array}$ & Q6CFH1 & $81 / 12 / 87$ & $22.0 / 4.8$ & $20.2 / 5.30$ \\
\hline $27 \ddagger$ & $\begin{array}{c}\text { YALI0D08184p, SSA4 heat shock protein of HSP70 } \\
\text { family, fragment }\end{array}$ & Q6C9V0 & $115 / 27 / 28$ & $21 / 4.8$ & $70.3 / 4.9$ \\
\hline 28 & $\begin{array}{c}\text { YALIOF08327p } \\
(139 \text { a.o. })\end{array}$ & Q6C2F6 & $111 / 7 / 51$ & $22.0 / 4.6$ & $14.7 / 4.6$ \\
\hline $29 \ddagger$ & $\begin{array}{c}\text { YALI0A10879p E3 ubiquitin ligase complex } \\
\text { SCF subunit } \\
\text { (162 a.o.) }\end{array}$ & XP_499961 & $84 / 4 / 43$ & $18.5 / 0 / 4.6$ & $18.3 / 4.4$ \\
\hline $30 \ddagger$ & $\begin{array}{l}\text { YALI0E32736p, Bis(5'-adenosyl)-triphosphatase } \\
\text { (169 a.o.) }\end{array}$ & XP_002143095.1 & $163 / 13 / 69$ & $17.7 / 5.1$ & $18.7 / 5.2$ \\
\hline $31 \ddagger$ & $\begin{array}{l}\text { Calcium binding protein YALI0E03388p } \\
\text { (147 a.o) }\end{array}$ & Q6C765 & $162 / 15 / 79$ & $17.0 / 4.7$ & $16.8 / 4.8$ \\
\hline 34 & $\begin{array}{c}\text { YALI0A10747p (Ribosome maturation } \\
\text { protein family) } \\
\text { (117 a.o.) }\end{array}$ & Q6CHA5 & $193 / 10 / 78$ & $13.0 / 5.5$ & $13.1 / 5.2$ \\
\hline $35 \ddagger$ & $\begin{array}{c}\text { YALI0C03443p } \\
\text { (small heat shock protein (HSP20) family) } \\
\text { (149 a.o.) }\end{array}$ & Q6CD64 & $135 / 13 / 79$ & $17.5 / 6.2$ & $17.3 / 5.6$ \\
\hline 36 & $\begin{array}{c}\text { YALI0F08393p, Nascent polypeptide-associated } \\
\text { complex subunit beta } \\
\text { (162 a.o.) }\end{array}$ & XP_505159.1 & $279 / 20 / 92$ & $18.3 / 5.50$ & $17.3 / 5.5$ \\
\hline 41 & $\begin{array}{l}\text { YALI0C17347p, SSC1 Heat shock protein } \\
647 \text { a.o., fragment }\end{array}$ & Q6CBM2 & $148 / 15 / 28$ & $22.5 / 6.2$ & $70.0 / 5.4$ \\
\hline
\end{tabular}

*S/M/C-the Mascot Score is an indicator of conformity or "scorecard"; match peptides are the number of matched peptides; coverage is the percentage of the complete amino acid sequence of the protein using the identified peptides. ${ }^{* *} \mathrm{M}_{\mathrm{M}} / \mathrm{pI}$ (exp.) are the obtained estimates according to electrophoretic mobility in the $\mathrm{DE}, \mathrm{M}_{\mathrm{M}} / \mathrm{pI}$ (calc.) are the estimates made using the data on the amino acid sequence, taking into account signal peptide removal, but with no consideration of other post-synthetic modifications using the ExPASy Compute $\mathrm{pI} / \mathrm{M}_{\mathrm{w}}$ tool software. $¥$ Marks the protein in the composition of the mixtures in the protein spots. 
Comparative analysis of 2-DE gels revealed nine proteins with increased expression under alkaline stress (Figures 2 and S3C, Table 3). Among the up-regulated proteins at an alkaline $\mathrm{pH}$, there are two folding proteins, namely 39 (YALIOC10230p, peptidyl-prolyl cis-trans isomerase) and zone 26 (YALIOF02805p, HSP60 heat shock protein-chaperone); two proteins of glycolysis: zone 22 (YALI0C06369p, glyceraldehyde-3-phosphate dehydrogenase) and zone 40 (YALI0F05214p, triose phosphate isomerase) (Figure S3C). In addition, some mitochondrial proteins were identified, namely the outer membrane porin (zone 20, YALIOF17314p) and malate dehydrogenase (zone 21, YALI0D16753p); the ribosomal protein (zone 33, A0A1H6Q0M6), and the protein involved in the nucleotides synthesis (zone 35, YALI0F09229p) (Figure S3C). Among the proteins down-regulated under alkaline stress, we obtained three proteins of oxidative phosphorylation, namely 29, YALIOD2202p; 30, YALIOE19723p, and 31, YALI0E10144p (Figure S3D). The protein of cell wall synthesis (zone 23, YALI0B03564p), 60-S ribosomal ubiquitin (zone 37), and thioredoxin YALIOF01496p (zone 32) also significantly decreased in their amounts (Table 4, Figure S3D).

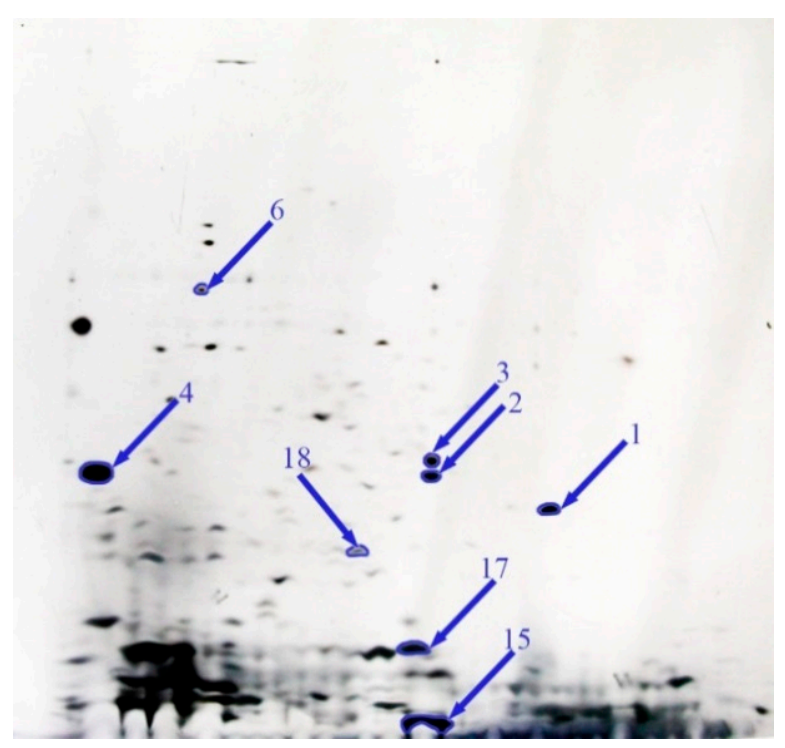

(A)

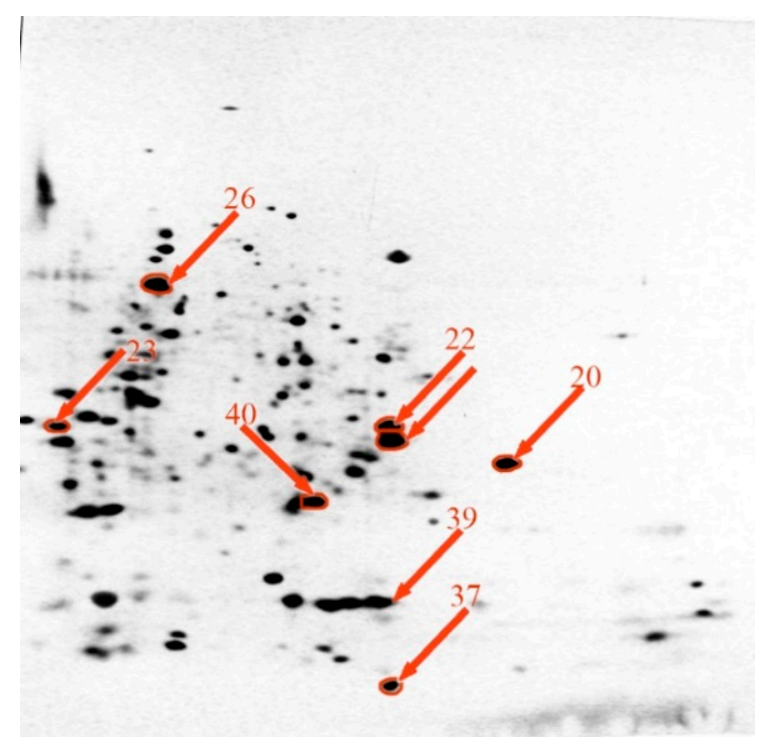

(B)

Figure 2. Comparative proteomics analysis of the effect of alkaline stress on protein expression. Summary of various expression levels of Y. lipolytica total protein extracted under normal (A) and alkaline (B) stress conditions. Symbols: overexpressed proteins under normal (blue arrow) and alkaline stress (red arrow) condition.

Table 3. The list of up-regulated proteins in response to alkaline stress in the Y. lipolytica yeast using mass spectrometry (MALDI-TOF MS and MS/MS) under alkaline conditions.

\begin{tabular}{|c|c|c|c|c|c|}
\hline $\begin{array}{l}\text { Spot } \\
\text { Number }\end{array}$ & Protein Name & $\begin{array}{l}\text { NCBI or } \\
\text { UniProt ID }\end{array}$ & $\mathrm{S} / \mathrm{M} / \mathrm{C}^{*}$ & $\begin{array}{l}\mathrm{M}_{\mathrm{M}} / \mathrm{pI} \\
(\mathrm{expt.}) * *\end{array}$ & $\begin{array}{l}\mathrm{M}_{\mathrm{M}} / \mathrm{pI} \\
\text { (calc.) } * *\end{array}$ \\
\hline 20 & YALI0E12134p, Mitochondrial porin(285 a.o.) & Q6C1D2 & $505 / 37 / 96$ & $27.0 / 8.9$ & $27 / 8.8$ \\
\hline 21 & YALI0D16753p, Malate dehydrogenase(338 a.o.) & Q6C8V3 & $568 / 42 / 89$ & $31.0 / 8.5$ & $35.8 / 8.5$ \\
\hline 22 & $\begin{array}{l}\text { YALI0C06369p, Glyceraldehyde-3-phosphate } \\
\text { dehydrogenase(331 a.o.) }\end{array}$ & Q6CHQ6 & $325 / 28 / 68$ & $32.0 / 8.5$ & $35.8 / 6.6$ \\
\hline 26 & $\begin{array}{l}\text { YALIOF02805p, HSP60 heat shock } \\
\text { protein-chaperone(574 a.o.) }\end{array}$ & Q6C342 & $532 / 53 / 66$ & $57.0 / 5.4$ & $60.5 / 6.6$ \\
\hline 33 & A0A1H6Q0M6, 40S ribosomal protein S14 & A0A1H6Q0M6 & $287 / 14 / 72$ & $9 / 5.8$ & $15.4 / 5.7$ \\
\hline $35 \ddagger$ & YALI0F09229p, Nucleoside diphosphate kinase & Q6CF90 & $76 / 7 / 56$ & $16 / 5.9$ & $17.2 / 6.3$ \\
\hline
\end{tabular}


Table 3. Cont.

\begin{tabular}{|c|c|c|c|c|c|}
\hline $\begin{array}{c}\text { Spot } \\
\text { Number }\end{array}$ & Protein Name & $\begin{array}{c}\text { NCBI or } \\
\text { UniProt ID }\end{array}$ & $\mathrm{S} / \mathrm{M} / \mathrm{C}^{*}$ & $\begin{array}{c}\mathrm{M}_{\mathbf{M}} / \mathrm{pI} \\
(\operatorname{expt.)} * *\end{array}$ & $\begin{array}{c}\mathbf{M}_{\mathbf{M}} / \mathbf{p I} \\
\text { (calc.) } * *\end{array}$ \\
\hline 38 & YALI0E12133p & Q6C662 & $200 / 14 / 91$ & $15 / 6.7$ & $15.9 / 5.9$ \\
\hline 39 & YALI0C10230p, Peptidyl-prolyl cis-trans isomerase & Q6CCD9 & $108 / 10 / 77$ & $15 / 6.7$ & $17.8 / 6.9$ \\
\hline 40 & YALI0F05214p, Triose phosphate isomerase & Q6C2T9 & $401 / 28 / 91$ & $23 / 6.5$ & $26.7 / 6.3$ \\
\hline
\end{tabular}

*S/M/C-The Mascot Score is an indicator of conformity or "scorecard"; match peptides are the number of matched peptides; coverage is the percentage of the complete amino acid sequence of the protein using the identified peptides. ${ }^{* *} \mathrm{M}_{\mathrm{M}} / \mathrm{pI}$ (exp.) are the obtained estimates according to electrophoretic mobility in the $\mathrm{DE}, \mathrm{M}_{\mathrm{M}} / \mathrm{pI}$ (calc.) are the estimates made using the data on the amino acid sequence, taking into account signal peptide removal, but with no consideration of other post-synthetic modifications using the ExPASy Compute $\mathrm{pI} / \mathrm{M}_{\mathrm{w}}$ tool software. ${ }^{\ddagger}$ Marks the protein in the composition of the mixtures in the protein spots.

Table 4. The list of down-regulated proteins in response to alkaline stress in the Y. lipolytica yeast using mass spectrometry (MALDI-TOF MS and MS/MS) under alkaline conditions.

\begin{tabular}{cccccc}
\hline $\begin{array}{c}\text { Spot } \\
\text { Number }\end{array}$ & Protein Name & $\begin{array}{c}\text { NCBI or } \\
\text { UniProt ID }\end{array}$ & S/M/C * & $\begin{array}{c}\mathbf{M}_{\mathbf{M}} / \mathbf{p I} \\
(\mathbf{e x p t . )}\end{array}$ & $\begin{array}{c}\mathbf{M}_{\mathbf{M}} / \mathbf{p I} \\
(\mathbf{c a l c})\end{array}$ \\
\hline 23 & YALI0B03564p, 1,3-beta-glucanosyltransferase activity & Q6CFU7 & $302 / 23 / 68$ & $33 / 4$ & $34.1 / 4.5$ \\
\hline $29 \ddagger$ & YALI0D2202, ATP synthase subunit delta & Q6C877 & $84 / 4 / 73$ & $16 / 4$ & $14.8 / 4.4$ \\
\hline $30^{\ddagger}$ & YALI0E19723p, cytochrome-c oxidase chain IV & Q6C5A3 & $116 / 10 / 72$ & $15 / 5$ & $17.6 / 5.2$ \\
\hline $31 \ddagger$ & YALI0E10144p, cytochrome-c oxidase subunit VI & Q6C6E6 & $93 / 15 / 45$ & $12 / 4.5$ & $17 / 4.8$ \\
\hline 32 & YALI0F01496p, Thioredoxin & Q6C399 & $162 / 16 / 81$ & $10 / 4.2$ & $11.5 / 4.6$ \\
\hline 37 & Ubiquitin-60S ribosomal protein L40 fusion & Q6C2D7 & $91 / 22 / 53$ & $9 / 7$ & $14.8 / 9.8$ \\
\hline
\end{tabular}

*S/M/C-The Mascot Score is an indicator of conformity or "scorecard"; match peptides are the number of matched peptides; coverage is the percentage of the complete amino acid sequence of the protein using the identified peptides. ${ }^{* *} \mathrm{M}_{\mathrm{M}} / \mathrm{pI}$ (exp.) are the obtained estimates according to electrophoretic mobility in the $\mathrm{DE}, \mathrm{M}_{\mathrm{M}} / \mathrm{pI}$ (calc.) are the estimates made using the data on the amino acid sequence, taking into account signal peptide removal, but with no consideration of other post-synthetic modifications using the ExPASy Compute $\mathrm{pI} / \mathrm{M}_{\mathrm{w}}$ tool software. $¥$ Marks the protein in the composition of the mixtures in the protein spots.

Eight protein spots showing the abundance at least 1.7-fold or more in the alkaline conditions were identified (Figure 3), namely zones 20 (mitochondrial porin VDAC), 21 (malate dehydrogenase), 22 (glyceraldehyde-3-phosphatedehydrogenase), 39 (peptidylprolyl cis-trans isomerase, modified peptidyl-prolyl cis-transisomerase), and 40 (triose phosphate isomerase) (Figure 3). The expression of proteins 40, 22, and 26 showed the most increase, namely by 3.3, 3.5, and 3.9 times, respectively (Figure 3 ). The proteins of 23 (1, 3-beta-glucanosyltransferase) and 37 (ubiquitin) decreased in the spot volumes in the electrophoretogram by 0.4 and 0.68 times, respectively (Figure 3). $\mathrm{Cu} / \mathrm{Zn} \mathrm{SOD}$ YALI0E12133p was the only protein with an unchanged level of expression (zone 16, Figure 1, Table S1). 


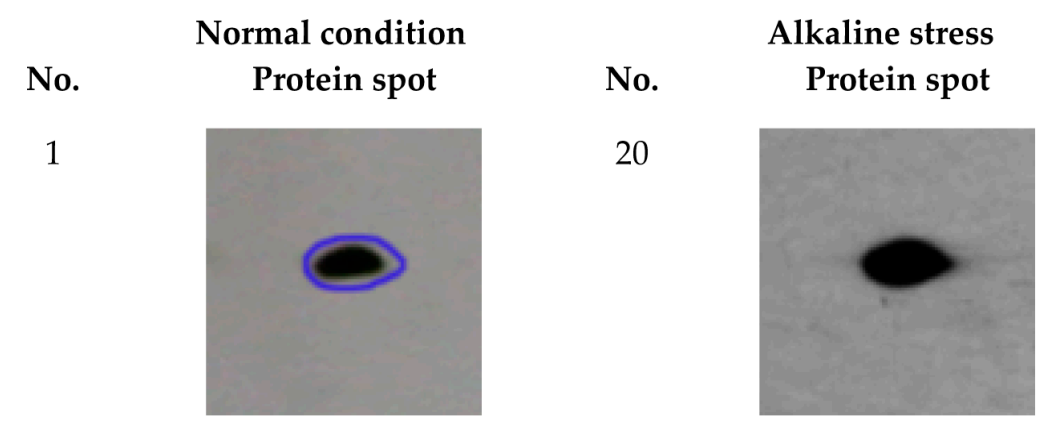

Protein name,

spot intensity comparison

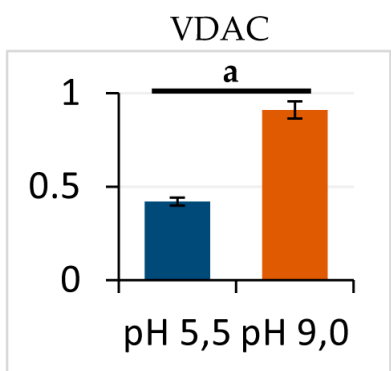

2

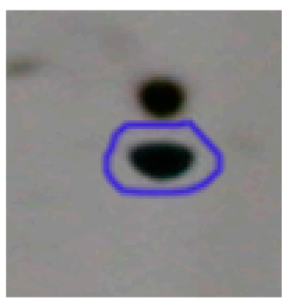

21

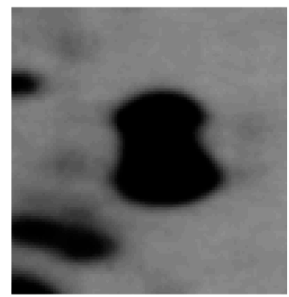

Malate dehydrogenase

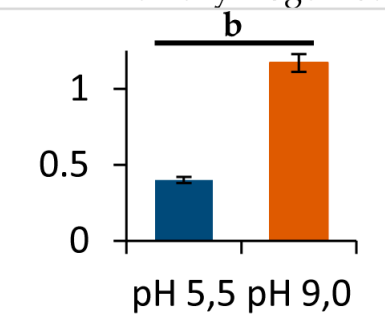

3

22

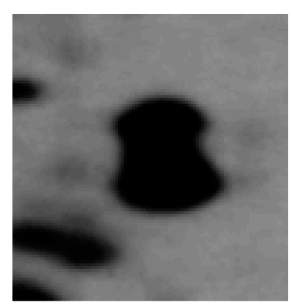

Glyceraldehyde-3phosphatedehydrogenase

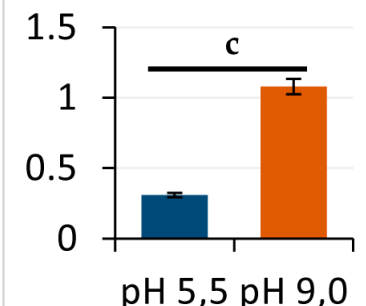

1,3-beta-glucanosyltransferase

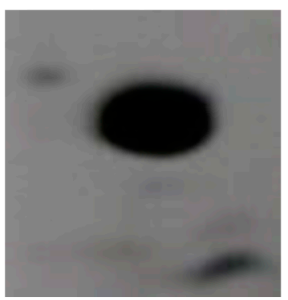

23
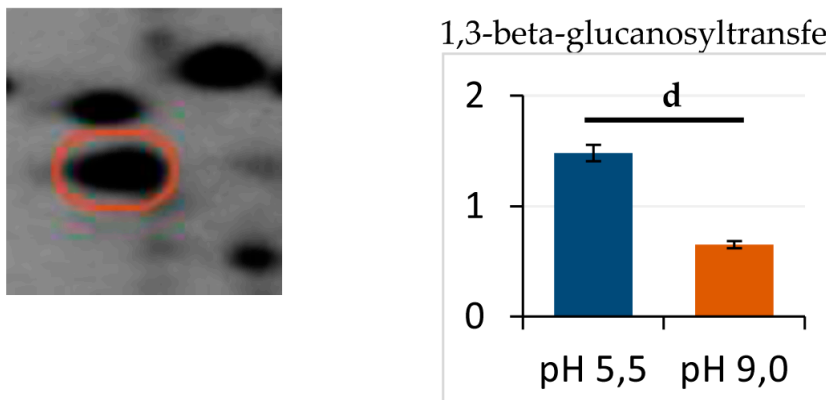

Figure 3. Cont. 

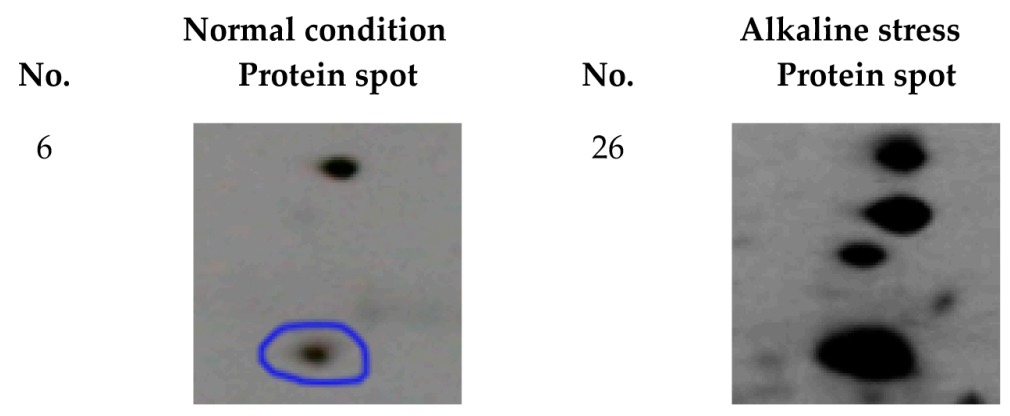

\section{Protein name, spot intensity comparison}

HSP60 heat shock protein - chaperone

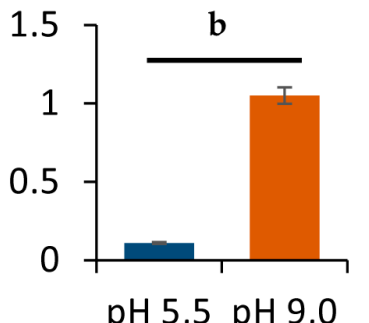

$\mathrm{pH} 5,5 \mathrm{pH} \mathrm{9,0}$

15

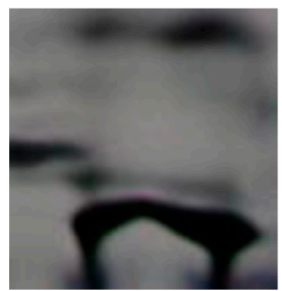

17

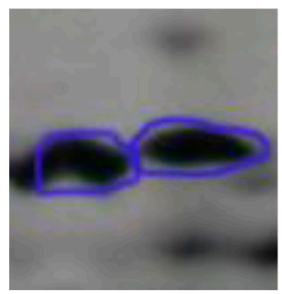

18

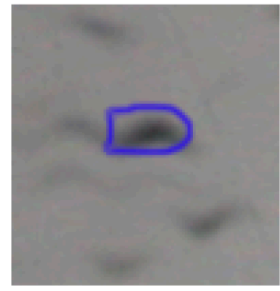

37

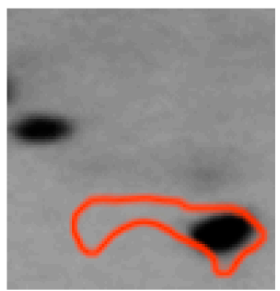

39

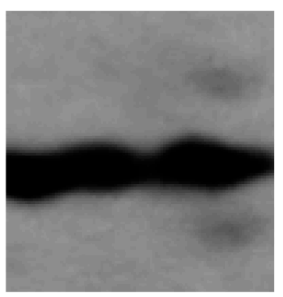

40

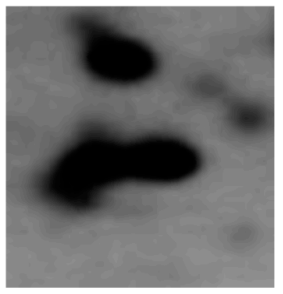

Ubiquitin

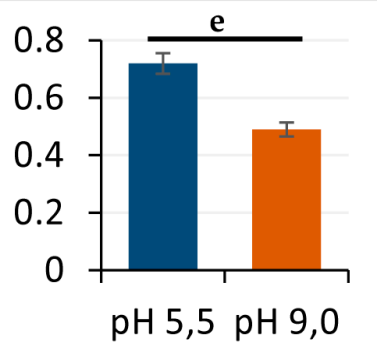

Peptidyl-prolyl cis-trans isomerase, Modified peptidyl-prolyl cistransisomerase

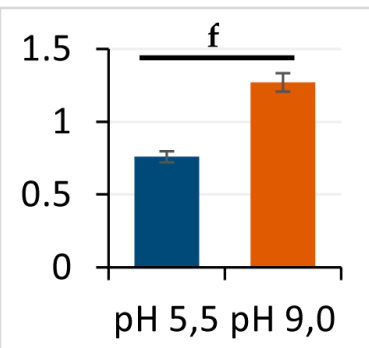

Triose phosphate isomerase

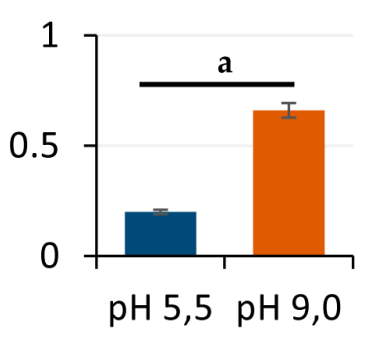

Figure 3. Enlarged sectors of the 2-DE gels including the identified proteins, which were differentially expressed under normal (left) and alkaline stress (right) conditions. The rightmost column shows the normalized amount of each protein spot. a- $p<0.04$; $\mathrm{b}-p<0.05 ; \mathrm{c}-p<0.03 ; \mathrm{d}-p<0.02 ; \mathrm{e}, \mathrm{f}-$ did not differ significantly. Values are mean \pm S.E.M from five independent experiments and three analytical replicates. Symbols: overexpressed proteins under normal (blue circle) and alkaline stress (red circle) condition.

The structural protein of YALI0B20306p (zone 5, cell wall mannoprotein) is one of typical proteins for the normal conditions (Table 1). The yeast cell wall is known as the 
main barrier providing cell osmotic stability and protects it from an alkaline environment. Its composition mainly consists of neutral carbohydrates (70\%), amino sugars (7\%), proteins $(15 \%)$, lipids $(5 \%)$, and phosphates $(0.8 \%)$. The $Y$. lipolytica cell wall usually contains mannan, $\beta$-glucan, and chitin as the main structural and storage polysaccharides. Unlike glucans and chitin, mannan undergoes alkaline hydrolysis [18-20]. Mannans are usually included in the wall outer part, while the inner surface is composed of chitins and glucans. Mannoproteins are covalently bound to cell wall mannans via either Nglycosidic or O-glycosidic bonds. The latter is more labile at an alkaline $\mathrm{pH}$ [21]. The expression of mannoprotein (Pir1) YALI0B20306p only in the yeast grown at pH 5.5 and $29^{\circ} \mathrm{C}$ indicates its instability at an alkaline $\mathrm{pH}$ and $37{ }^{\circ} \mathrm{C}$. Chaperones play a crucial role in the native conformation maintenance of proteins at osmotic stress. At an alkaline $\mathrm{pH}$, we observed a 9.6-fold increase in the HSP60 heat shock protein YALI0F02805p (zone 26, Table 3, Figure 3) belonging to the HSP60 chaperone family, which support the synthesis and conformation of mitochondrial proteins. Previously, it was recorded that HSP60 chaperones are involved in folding and post-translational alterations of the mitochondrial proteins and imported proteins synthesized on the inner mitochondrial membrane [22,23]. The STRING database data (http:/ / string-db.org/; accessed on 26 October 2021) show the interaction of YALIOF02805p with both HSP70 chaperones and the GroES chaperonin family and with ATP synthase subunit beta in the Y. lipolytica yeast (Figure 4A). The adaptation to alkaline conditions is likely to raise the participation role of HSP60 chaperones to support the protein conformation. At $\mathrm{pH}$ 9.0, two expression proteins, namely heat shock protein 70-related protein SSC1 mitochondrial precursor YALI0C17347p (zone 41, Table 2), interacting with HSP60 heat shock protein, and YALI0C03443p (small heat shock protein (HSP20) family), were identified.

However, the PPIase or rotamase YALI0C10230g (No 39, Table 3) increased, facilitating the cytoplasmic proteins' folding. According to the STRING database (http:/ / string-db.org/; accessed on 26 October 2021), the YALI0C10230g protein tightly interacts with the histone deacetylation system (YALIOB20262p and Histone deacetylase proteins) (Figure 4B), which regulates the transcription processes under these conditions [24]. The decreased share of ubiquitin-60S ribosomal protein L40 fusion protein (No 37, Table 4) regulating the ribosomes' assembly and the expression of the 26S ribosomal regulatory unit YALI0B09339p (zone 24, Table 3) also indicate some disturbances in the ribosomes' structural organization (some damage to the ribosome assembly during growth at an alkaline $\mathrm{pH}$ ). One of the up-regulated proteins that was activated under alkaline conditions was YALI0C06369p, glyceraldehyde-3phosphate dehydrogenase (No. 22, Table 3). The changes in carbohydrate metabolism play a key role in the adaptation of the Y. lipolytica yeast upon growth using glycerol at alkaline $\mathrm{pH}$ values. Previously, we showed a slight decrease in the storage lipids' accumulation by $25-27 \%$ and cytosol soluble carbohydrates by 1.6 times under these conditions [4]. 
A

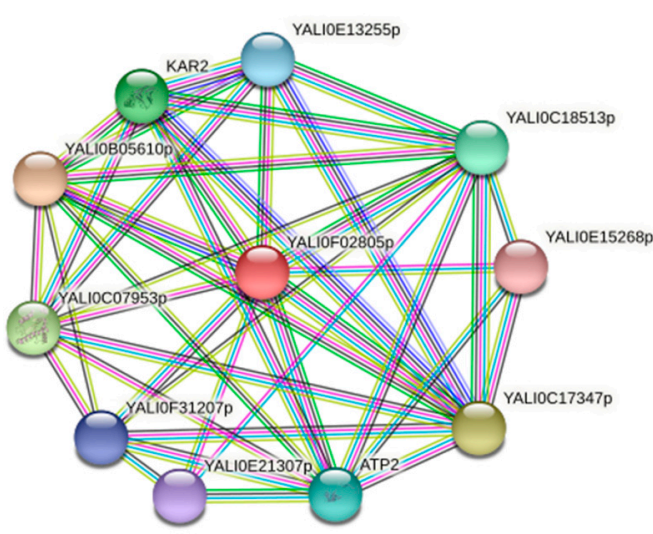

C

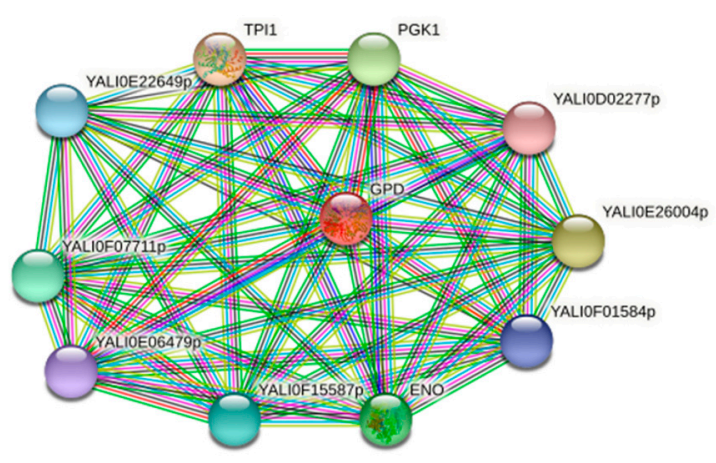

E

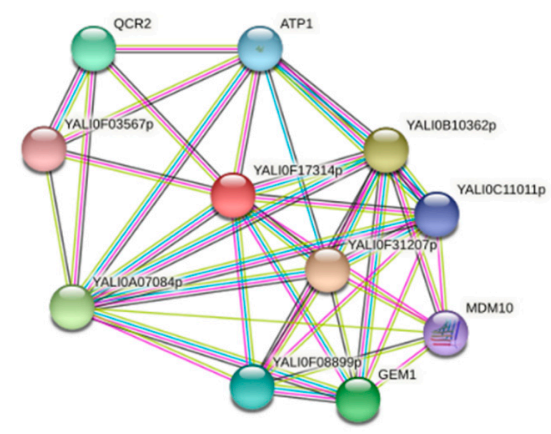

B

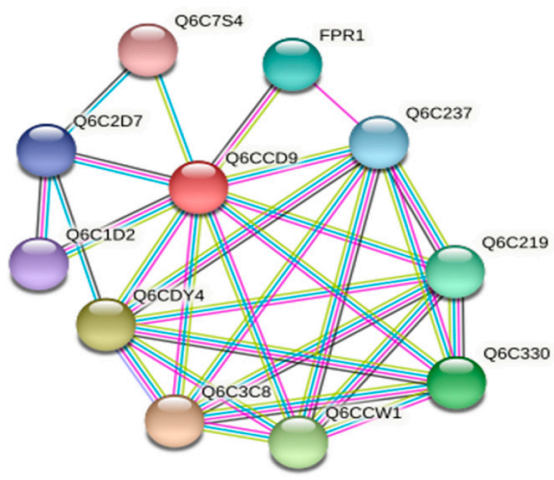

D

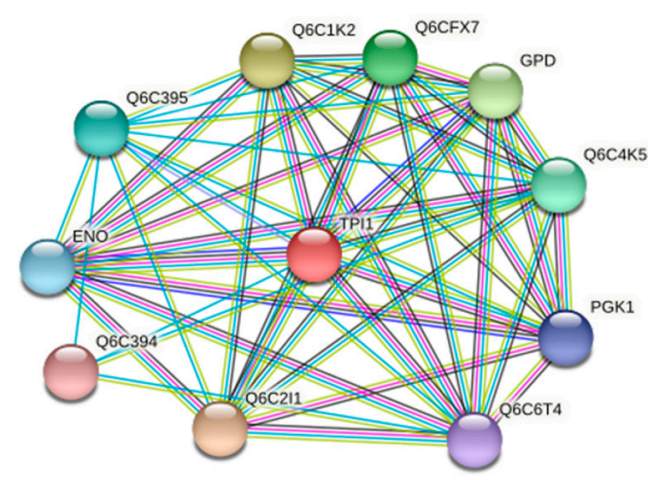

$\mathbf{F}$

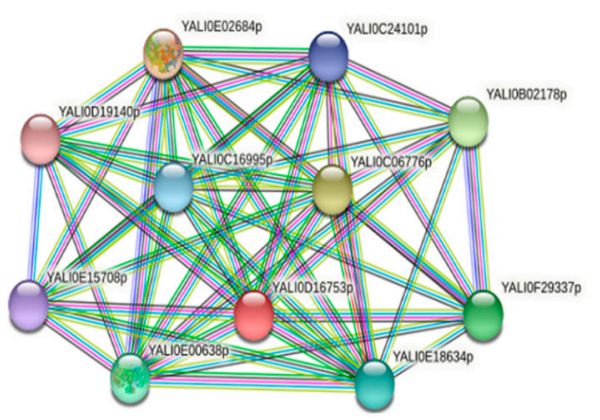

Figure 4. Network analyses of functional associations and/or interactions of up-regulated proteins upon the adaptation to alkaline stress. Different clusters of interacting proteins were identified using the STRING software with the highest conformity score. The information on the proteins is summarized in the Supplementary Section (Table S2). (A) HSP60 heat shock protein—chaperone (YALI0F02805p) (B) Peptidyl-prolyl cis-trans isomerase (YALI0C10230p) (C) Glyceraldehyde-3phosphate dehydrogenase (YALI0C06369p) (D) Triose phosphate isomerase (YALI0F05214p) (E) VDAC (YALIOF17314p) (F) Malate dehydrogenase (YALI0D16753p).

However, mannitol remained the main carbohydrate, while glucose made up no more than $5.5 \%$ of the soluble carbohydrate pool. According to [25], growth of Y. lipolytica using glycerol leads to a higher oxygen consumption compared to that using glucose. This suggests that glycerol should be involved in general carbon metabolism with the participation of glycerol-3-dehydrogenase related to the mitochondrial membrane. This speculation 
is confirmed by the fact that the protein tightly interacts with the glycolysis enzymes of phosphoglycerate kinase; YALI0D12400p, glucose-6-phosphate isomerase; YALI0F07711p, and triosephosphate isomerase; YALI0F01584p (Figure 4C). Glyceraldehyde-3-phosphate dehydrogenase interacts with triosephosphate isomerase, YALI0F05214p (No 40). Its expression increased 3.3-fold under alkaline conditions (Figure 3). We showed this is in a previous study [12].

The TPI activation and a shift of the dihydroxyacetone phosphate conversion into glyceraldehyde-3-phosphate followed by its transformation into glycerate-1,3-bisphosphate and NADH formation at the background of GAPDH activation were revealed. So, we could expect a slight decline in metabolites' participation in gluconeogenesis, but maintaining a general scheme focus to form carbohydrates (mannitol) and lipids, as shown before. Triose phosphate isomerase is able to set a rapid balance between dihydroxyacetone phosphate and glyceraldehyde-3-phosphate formed by aldolase during glycolysis, which is associated with the pentose phosphate pathway and lipid metabolism via triosephosphates. Coactivation of triose phosphate isomerase and GAPDH accelerates glycerol transformation to pyruvate (Figure 4D). In this study, in the proteomic profile of the culture grown under alkaline stress, the mitochondrial porin VDAC (YALIOE12134p, mitochondrial porin (No. 20, Table 3) increased 2.2-fold (Figure 3). This is in good agreement with our previous studies performed using Yarrowia lipolytica Polf [12].

VDAC porins are known as conservative mitochondrial proteins regulating metabolite transport between the mitochondria and cytoplasm under both physiological and stress conditions [26,27]. VDAC is also involved in the regulation of respiration, ROS homeostasis, and yeast stress tolerance. The Saccharomyces cerevisiae mutants in the gene encoding mitochondrial porin synthesis are hyper sensitive to assimilating non-fermentable substrates (i.e., glycerol) due to the decreased respiratory activity [28]. VDAC is shown to play a positive role in carbon/energy stress signaling by providing nuclear location of AMPK/Snf1 signal transduction factors. The protein kinase Snf1 belongs to the family of AMP-activated protein kinases (AMPK). The positive regulation of AMPK/Snf1 with the VDAC participation was demonstrated using the Saccharomyces cerevisiae yeast. However, the conservatism of these proteins in eukaryotes suggests extending the phenomenon to some other organisms [29]. VDACs porins also provide the synthesis of cardiolipin and phosphatidylethanolamine in the inner mitochondria membrane, by transporting their precursors, namely phosphatidic acid and phosphatidylserine [30]. The increase in the porin level correlates with the rise in phoshatidic acid's share in membrane lipids, which increases by 1.6 times at an alkaline $\mathrm{pH}$ [4]. The porin closely interacts with YALI0F31207p, YALI0B10362p, and YALI0A07084p proteins, which possess porin activity and import proteins into mitochondria. It also acts with mitochondrial GTPase and mitochondrial membrane ATP synthase involved in mitochondria transport and energy synthesis (Figure 4E).

At an alkaline $\mathrm{pH}$, in the yeast proteomic profile, the share of malate dehydrogenase YALI0D16753p (No 21) involved in carbohydrate metabolism (Table 3) also increased. Malate dehydrogenase, being a mitochondrial protein, catalyzes the conversion of malate to oxaloacetate, forming NADH in the tricarboxylic acid cycle [31]. It increased 2.9-fold when grown at an alkaline ambient $\mathrm{pH}$ (Figure 3). Malate dehydrogenase activation can accelerate the formation of citrate with a concurrent shift to lipid synthesis. The STRING database confirms this speculation by presenting the data regarding the close relationships of the enzyme with citrate synthase YALI0E02684p, citrate synthase, YALIOE00638p, and fumarate hydratase YALI0C06776p (Figure 4F). The malate dehydrogenase induction indicates the key role of mitochondria in metabolic readjustment and active VDAC participation in the adaptation to alkaline stress.

\subsection{Changes in the Proteomic Profile of the Culture Grown under Heat Stress}

The growth of the yeast under the increased (up to $38^{\circ} \mathrm{C}$ ) growth temperature led to the evanescence of both zone 5 (mannoprotein (Pir1, YALI0B20306p) and zone 23 (1,3-betaglucanosyl-transferase YALIOB03564p), similarly to those in the alkaline conditions. Per- 
haps the proteomics changes are associated with the glycosidic bonds thermolability under those conditions. There was also revealed no VDAC porin (zone 20) in the profile. Thermal stress promoted the synthesis of 12 authentic proteins, and several proteins with chaperone features were substituted for some others (Figure 1 and Figure S4A, Table 5). Thus, in these conditions, we could note a few new proteins, namely 42 (YALI0D22352p, SSA4 heat shock protein), 43 (CPAR2_700380, heat shock protein 70 family), 44 (YALI0E35046p, SSA4 heat shock protein), and 53 (YALI0D22352p, SSA4 heat shock protein) (Table 5). According to the STRING database, SSA4 heat shock protein of the HSP70 family (No. 42) could interact with the proteins with chaperone properties of YALI0F00880p and YALI0C07953p, which are responsible for the cell response to heat stress (Figure 5A). Moreover, within their interactions, there are the proteins of the YALI0C08987p and YALIOA00594p HSP families (Figure 5A), which are also in charge of cellular protein structural and functional integrity (Figure S4A). In addition, among interacting proteins, clathrin was identified, which participates in clathrin-mediated endocytosis by absorbing the substances during the process and in the induction of the transmembrane carriers of amino acids, glucose, ions, etc. [32].

Table 5. List of differentially expressed proteins in response to heat stress in the Y. lipolytica yeast using mass spectrometry (MALDI-TOF MS and MS/MS).

\begin{tabular}{|c|c|c|c|c|c|}
\hline $\begin{array}{l}\text { Spot } \\
\text { Number }\end{array}$ & Protein Name & $\begin{array}{l}\text { NCBI or } \\
\text { UniProt ID }\end{array}$ & $\mathrm{S} / \mathrm{M} / \mathrm{C}^{*}$ & $\begin{array}{l}\mathrm{M}_{\mathrm{M}} / \mathrm{pI} \\
(\text { expt.) }\end{array}$ & $\begin{array}{l}\mathbf{M}_{\mathbf{M}} / \mathrm{pI} \\
\text { (calc.) ** }\end{array}$ \\
\hline 42 & YALI0D22352p, SSA4 heat shock protein & Q6C864 & $112 / 4 / 9$ & $34 / 5.0$ & $70.1 / 5.1$ \\
\hline 43 & CPAR2_700380, heat shock protein 70 family & G8BL45 & $141 / 10 / 27$ & $36 / 5.0$ & $61.2 / 5.0$ \\
\hline 43 & $\begin{array}{l}\text { CPAR2_106080, Mitochondrial import inner } \\
\text { membrane translocase TIM40 }\end{array}$ & G8B7Y8 & $129 / 7 / 18.5$ & $36 / 5.0$ & $33 / 5.2$ \\
\hline 44 & YALI0E35046p, SSA4 heat shock protein & Q6C3G5 & $84 / 5 / 9$ & $23 / 4.5$ & $70.1 / 5.0$ \\
\hline 45 & YALIOF20856p, Cofilin & Q6C0Y0 & $83 / 2 / 10$ & $18 / 5$ & $17.02 / 5.3$ \\
\hline 46 & CPAR2_203450, Formate dehydrogenase & G8BFR8 & $127 / 5 / 15$ & $17 / 5.0$ & $15.0 / 5.7$ \\
\hline 47 & CPAR2_401230, Fructose-bisphosphate aldolase & G8BI56 & $137 / 4 / 13$ & $17 / 8.0$ & $39.8 / 5.4$ \\
\hline 48 & $\begin{array}{l}\text { Q0ZIC1_CANPA, GTPase cytoplasmic elongation } \\
\text { factor } 1 \text { alpha }\end{array}$ & Q0ZIC1 & $148 / 6 / 33$ & $23 / 8.7$ & $27.4 / 8.5$ \\
\hline 49 & CPAR2_802980 & G8BC83 & $250 / 15 / 27$ & $20 / 4.0$ & $56.4 / 6.5$ \\
\hline 50,51 & YALI0B22506p, Formate dehydrogenase & Q6CDN8 & $86 / 5 / 18$ & $20 / 5.3$ & $40.3 / 6.5$ \\
\hline 52 & CPAR2_200490, Thioredoxin & G8BEL7 & $172 / 4 / 50$ & $11 / 6.5$ & $11.3 / 5.3$ \\
\hline 53 & YALI0D22352p, SSA4 heat shock protein & Q6C864 & $173 / 18 / 31$ & $23 / 62$ & $70.5 / 5.1$ \\
\hline 54 & CPAR2_500390, Cu/Zn SOD & G8BH89 & $201 / 12 / 68$ & $16 / 6.5$ & $16.2 / 5.4$ \\
\hline
\end{tabular}

*S/M/C-the Mascot Score is an indicator of conformity or "scorecard"; match peptides are the number of matched peptides; coverage is the percentage of the complete amino acid sequence of the protein using the identified peptides. ${ }^{* *} \mathrm{M}_{\mathrm{M}} / \mathrm{pI}$ (exp.) are the obtained estimates according to electrophoretic mobility in the $\mathrm{DE}, \mathrm{M}_{\mathrm{M}} / \mathrm{pI}$ (calc.) are the estimates made using the data on the amino acid sequence, taking into account signal peptide removal, but with no consideration of other post-synthetic modifications using the ExPASy Compute pI/M $\mathrm{w}$ tool software. 
A

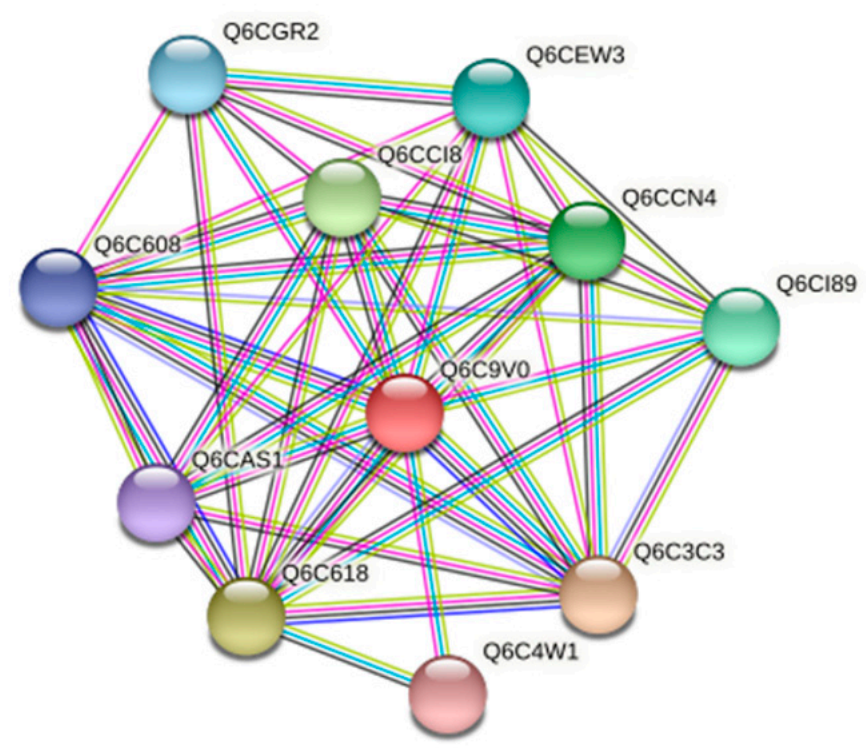

B

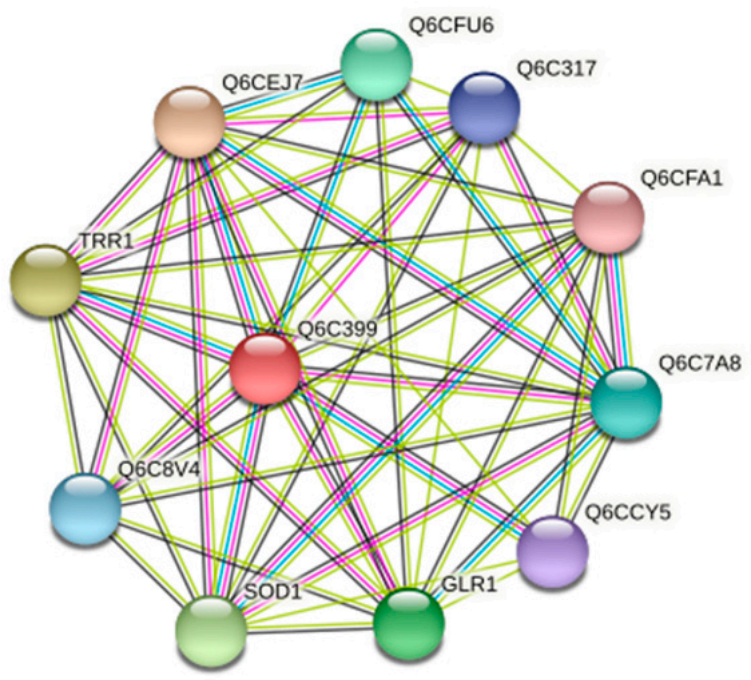

Figure 5. Network analyses of functional associations and/or interactions of induced proteins in response to heat stress. Different clusters of interacting proteins were identified using the STRING software with the highest conformity score. The information on the proteins is summarized in the Supplementary Section (Table S3). (A) SSA4 heat shock protein of HSP70 family (YALI0D08184p, YALIOD22352p) (B) Thioredoxin (CPAR2_200490).

Growth at an elevated temperature induced the expression of some new proteins involved in ribosomal synthesis (48, Q0ZIC1_CANPA, GTPase cytoplasmic elongation factor 1 alpha) and the structural organization of the cell, in particular, cofilin interacting with actin (45, YALIOF20856p, Cofilin) (Figure S4A). In addition, we obtained some antioxidant defense proteins (52, CPAR2_200490, Thioredoxin) and three formate dehydrogenases (46, CPAR2_203450; 50, YALI0B22506p (fragment), and 51, CPAR2_203450) (Figure S4A). The cofilin family contains the most important actin-binding proteins, which, being the main regulators of actin dynamics (severing, depolymerizing, nucleating, and bundling activities), possess a high level of conservatism in all eukaryotes, beginning from lower ones to mammals $[33,34]$. An essential cytoskeleton readjustment is likely to happen under the conditions of heat stress. The activity of cofilin is known to be influenced by redox modifications of Cys residues via disulfide bonds, S-glutathionylation, and S-nitrosylation [34]. The oxidized cofilin is dephosphorylated at Ser-3, impairing its actin-depolymerizing function. Consequently, cofillins play multiple roles in the cells through various pathologies at high temperatures.

Fructose-biphosphate aldolase (zone 47, CPAR2_401230), participating in glycolysis and gluconeogenesis, and an uncharacterized protein of 49 (CPAR2_802980) were also expressed in these conditions. There was no ubiquitin-60S ribosomal protein L40 fusion protein, which supports the structural organization of ribosomes in the cells. Evidently, the expressed chaperones perform this function. Previously, we showed that the culture growth of $38{ }^{\circ} \mathrm{C}$ was accompanied by dramatic changes in the soluble carbohydrates composition. Trehalose substituted the dominating carbohydrate of mannitol [4]. In the paper by [35], the authors showed that the Y. lipolytica yeast needs trehalose to survive at an increased temperature. The changes in the carbohydrate composition correlate with the changes in the yeast proteomic profile. The induction of fructose-bisphosphate aldolase (No. 47, Table 5) in the yeast growing in glycerol containing medium indicates the activation of gluconeogenesis needed for the trehalose synthesis. It is noteworthy to remark that although trehalose inhibits some glycolytic enzymes' activity in vitro, the enzymes' association removes this effect under oxidative stress [36]. Some decrease in the 
antioxidant enzymes' expression under heat stress is most likely to be partially counteracted by trehalose, possessing antioxidant activity. The expression of thioredoxin (No.52, Table 5) in the Y. lipolytica cells grown at an elevated temperature is apparently due to the cellular antioxidant response. The thioredoxin system includes three interacting proteins, namely thioredoxin, thioredoxin reductase, thioredoxin peroxidase, and NADPH as a proton source [37].

According to the STRING database, thioredoxin interacts with glutathione reductase, sulfiredoxin, and $\mathrm{Cu}-\mathrm{Zn}$ SOD (Figure 5B), in addition to the thioredoxin system (thioredoxin reductase). This confirms the high adaptive response of the cells to oxidative stress under these conditions. The induction of $\mathrm{NAD}^{+}$-dependent formate dehydrogenases and some other D-2-hydroxyacid dehydrogenases is evidently related to an increase in catabolic processes and the activation of one-carbon residue metabolism (Figure S4A). The formaldehyde expression in the cells appears due to the DNA demethylation, catabolism of serine, methionine, and purine bases [38]. Formate dehydrogenases are widely distributed in nature. Formaldehyde is one of C- 1 metabolism's products (one-carbon metabolism), and can form due to the catabolism of serine, methionine, and purine bases (1C units from serine to formate, and onto purines, thymidylate (dTMP), and methionine). DNA demethylation facilitates either formaldehyde or methanol, and formate dehydrogenase substrate expression. Functioning together with $\mathrm{NAD}^{+}$-dependent formaldehyde dehydrogenase and $\mathrm{NAD}^{+}$-dependent alcohol dehydrogenase, the enzymes contribute a lot to the NADH production via oxidizing the corresponding substrates, namely formate, formaldehyde, and methanol [39]. Therefore, we assume that the replenishment of the reducing equivalent pool could be used in the gluconeogenesis needed for the trehalose synthesis [4].

\subsection{Changes in the Cell Proteomics during Culture Growth under Combined Stress}

The assay of the DE gels showed the expression proteins typical to heat and combined stress (in the list, numbers 54 and 61 (CuZn SOD, CPAR2_500390, 2), 43 and 63 (30 kDa fragments of a protein of the HSP70 CPAR2_700380 family). Combined stress induced the synthesis of nine original proteins including two proteins involved in the translation process, namely the elongation factor (No. 57,CPAR2_20706) and protein 62 (SBDS domaincontaining protein) needed for ribosome assembly (Table 6, Figure S4B).

Among the proteins of energy metabolism, the ATP synthase subunit (No. 55, CPAR2_503440) and the pyruvate dehydrogenase subunit (No. 65, CPAR2_402950) were revealed (Figure S4B). Moreover, a $12 \mathrm{kDa}$ fragment of $36 \mathrm{kDa}$ glyceraldehyde-3-phosphate dehydrogenase CPAR2_808670 was identified (No. 60), and two $12 \mathrm{kDa}$ fragments of two different carbonyl reductases, CPCR1 and CPAR2_502580 (zones 56 and 58) were detected (Table 6). Nucleoside diphosphate kinase CPAR2_101390 (No. 59) and 22 kDa chaperone HSP70 Ssa2 HSP70 (zone 66) were two other original proteins (Table 6). It is noteworthy that under the conditions of alkaline $\mathrm{pH}$ and elevated temperature, the culture growth was accompanied by the changes in the proteomics, which were different from those at an alkaline $\mathrm{pH}$ and elevated temperatures. There was a change in the chaperone compositions (zones 63, 64, 66), there were no chaperone proteins either at an alkaline $\mathrm{pH}$ (No. 26, 27, 35, 41) (Table 2$)$ or at an elevated temperature $\left(37^{\circ} \mathrm{C}\right)($ No. $43,44,53)$ (Table 5). All the new chaperones identified belonged to the heat shock protein 70 family. 
Table 6. The list of differentially expressed proteins in response to combined stress in the Y. lipolytica cells using mass spectrometry (MALDI-TOF MS and MS/MS).

\begin{tabular}{|c|c|c|c|c|c|}
\hline $\begin{array}{l}\text { Spot } \\
\text { Number }\end{array}$ & Protein Name & $\begin{array}{l}\text { NCBI or } \\
\text { UniProt ID }\end{array}$ & $\mathrm{S} / \mathrm{M} / \mathrm{C}^{*}$ & $\begin{array}{l}\mathrm{M}_{\mathrm{M}} / \mathrm{pI} \\
(\exp .) * *\end{array}$ & $\begin{array}{l}\mathbf{M}_{\mathbf{M}} / \mathrm{pI} \\
\text { (calc.) } * *\end{array}$ \\
\hline 55 & CPAR2_503440, ATP synthase subunit 5 & G8BGX1 & $141 / 3 / 27$ & $20 / 9.5$ & $23.1 / 9.7$ \\
\hline 56 & CPCR1, Carbonyl reductase & H9DXW0 & $92 / 3 / 15$ & $14 / 8.7$ & $37.1 / 6.3$ \\
\hline 57 & CPAR2_207060, Elongation factor 1-alpha & G8BCR8 & $125 / 3 / 7$ & $14 / 8.5$ & $50 / 9.1$ \\
\hline 58 & CPCR1, Carbonyl reductase & H9DXW0 & $99 / 6 / 16$ & $12 / 8.7$ & $37.1 / 6.3$ \\
\hline 59 & CPAR2_101390, Nucleoside diphosphate kinase & G8B6L9 & $142 / 9 / 39$ & $13 / 7$ & $16.8 / 8.6$ \\
\hline 60 & $\begin{array}{c}\text { CPAR2_808670, } \\
\text { Glyceraldehyde-3-phosphate dehydrogenase }\end{array}$ & G8BB94 & $114 / 7 / 30$ & $13 / 6.5$ & $36.1 / 6.2$ \\
\hline 61 & CPAR2_500390, Cu/Zn SOD & G8BH89 & $148 / 7 / 61$ & $16 / 6.9$ & $16 / 5.4$ \\
\hline 62 & CPAR2_406210, SBDS domain-containing protein & G8BJK2 & $82 / 4 / 30$ & $13 / 5.3$ & $12.5 / 4.8$ \\
\hline 63,64 & CPAR2_700380, heat shock protein 70 family & G8BL45 & $146 / 13 / 26$ & $30 / 5$ & $61 / 5.0$ \\
\hline 65 & $\begin{array}{l}\text { CPAR2_402950, Pyruvate dehydrogenase E1 } \\
\text { component subunit beta }\end{array}$ & G8BIM8 & $142 / 3 / 10$ & $40 / 5$ & $42.1 / 5.0$ \\
\hline 66 & hsp70 chaperone, heat shock protein 70 family & H8X9S4 & $132 / 9 / 38$ & $23 / 5$ & $22.7 / 5.7$ \\
\hline
\end{tabular}

*S/M/C- the Mascot Score is an indicator of conformity or "scorecard"; match peptides are the number of matched peptides; coverage is the percentahe of the complete amino acid sequence of the protein using the identified peptides. ${ }^{* *} \mathrm{M}_{\mathrm{M}} / \mathrm{pI}$ (exp.) are the obtained estimates according to electrophoretic mobility in the $\mathrm{DE}, \mathrm{M}_{\mathrm{M}} / \mathrm{pI}$ (calc.) are the estimates made using the data on the amino acid sequence, taking into account signal peptide removal, but with no consideration of other post-synthetic modifications using the ExPASy Compute $\mathrm{pI} / \mathrm{M}_{\mathrm{w}}$ tool software.

Furthermore, several new spots were identified as carbonyl reductases (No. 56, 58), which belong to a large family of alcohol dehydrogenases and specialize in the asymmetric reduction of numerous compounds, namely aliphatic and aromatic ketones and diketones, keto acids, esters, and amides. Carbonyl reductases are of high stereoselectivity and are preferable as the NADH cofactor, being more thermostable than NADPH. Unlike most substrates, it is very stable in the presence of low-molecular-weight alcohols, such as isopropanol [40]. For example, carbonyl reductase isolated from Candida parapsilosis (CPCR; EC 1.1.1.1) could catalyze the asymmetric reduction of aliphatic and aromatic ketones and diketones [41]. The identification of several zones corresponding to the carbonyl reductases indicates the induction of catabolic processes related to scavenging the damaged proteins and lipids under combined stress (Figure S4B).

The repair of nucleic acids and the maintenance of the apparatus for the new proteins synthesis play the crucial role in the yeast adaptation to the elevated temperature under alkaline conditions. Evidently, it leads to an increase in the SBDS domain-containing protein (No. 62) share, elongation factor 1 (No. 57), and nucleoside diphosphate kinase (No. 59) (Table 6, Figure S4B). Upon growth at an alkaline $\mathrm{pH}$ and/or at an elevated temperature, the proteins of glycolysis/glyconeogenesis, which are involved in redistributing metabolic fluxes of carbon substrates, altered their composition (Figure S4B). Under the conditions of combined stress, the ratio of the carbohydrate metabolism proteins also changed. The increase in the glyceraldehyde-3-phosphate dehydrogenase (No. 60) and pyruvate dehydrogenase (No. 65) levels (Table 6) is supposed to redirect pyruvate to fatty acid synthesis. Interestingly, previously, we showed that under combined stress, triglycerides were converted into di- and monoglycerides with the background of the storage lipids' decrease compared to those under the normal growth conditions [4]. This may have occurred because the cells are in great demand for intensive protein synthesis and the energy for the synthesis under the conditions of oxidative stress (Figure S4B). The increased expression of ATP synthase subunit 5 (No. 55) (Table 6) providing these processes partly confirms the hypothesis [42].

The comparison of the expression protein profiles with regard to their functional properties in the $Y$. lipolytica yeast grown under various conditions was performed. The 
protein spots included a mixture of several proteins and also contained short fragments of some known proteins. It is noteworthy that the CPAR2 proteins, according to the Matrix Science database, are classified as belonging to the C. parapsilosis yeast. Under stress conditions, the $Y$ lipolytica culture is likely to synthesize some unknown forms of these proteins, which are closer to those from C. parapsilosis. Thus, we decided to compare the identified proteins according to their functions. Figure 6 shows the results of the comparison presented as the Venn diagram. Five proteins from the culture grown in the normal conditions proved quite original. Among them, there are two proteins of oxidative phosphorylation, namely $\beta$-subunit of ATP synthase (YALIOF03179p) and cytochrome c oxidase (cytochrome c oxidase); two structural proteins, i.e., the cell wall mannoprotein Pir1 (YALI0B20306p) and profilin (YALI0B07183p); and the thiol-specific peroxidase (YALI0A19426p) obligatory to maintain cell redox homeostasis. Such a set of proteins can be associated with active processes of cell growth and fission.

E3 ubiquitin ligase complex SCF subunit;

endopeptidase activator; small heat shock protein (HSP20);

SSC1 Heat shock protein; nascent polypeptide-associated complex subunit beta;

$\mathrm{NAD}(\mathrm{P}) \mathrm{H}$ dehydrogenase; bis(5'-adenosyl)-triphosphatase myosin regulatory light chain HSP60 $\uparrow$
OS ribosomal protein S14 $\mathrm{VDAC} \uparrow ;$
dyl-prolyl cis-trans isomerase $\uparrow$; tropomyosin $\uparrow$ triosephosphate isomerase $\uparrow$; malate dehydrogenase $\uparrow$;

ATP synthase subunit delta $\downarrow$; cytochrome-c oxidase subunit VI $\downarrow$;

cytochrome-c oxidase chain IV $\downarrow$; 1,3-beta-glucanosyltransferase $\downarrow$; ubiquitin-60S ribosomal protein $\downarrow$ formate dehydrogenase; fructose-bisphosphate aldolase; mitochondrial import inner membrane translocase;

$$
\text { cofilin }
$$

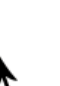


genase (YALI0B07007p) involved in the purine metabolism, bis (5'-adenosyl) triphosphatase (YALIOE32736p), chain IV of cytochrome c oxidase (YALI0E19723p), and myosin light chain (YALIOE0E033) are the four remaining proteins detected under alkaline stress (Figure 4). Among common proteins for the normal and alkaline conditions, there were eleven proteins. The expression of four of them decreased. Two of these are the proteins of oxidative phosphorylation, namely the $\delta$-subunit of ATP synthase (YALI0D22022p) and subunit VI of cytochrome c oxidase (YALI0E10144p). 1,3-beta-glucanosyltransferase (YALI0B03564p) and ubiquitin-60S, involved in carbohydrate metabolism, are the other two proteins. The expression of seven proteins increased under alkaline stress (Figure 4). Among them, there are VDAC (YALIOF17314p), two folding proteins, namely peptidyl-prolyl-cis-trans isomerase (YALI0C10230p), and $60 \mathrm{kDa}-\mathrm{HSP}$ chaperone (YALIOF02805p). Alkaline stress also caused the increased expression of 40S ribosomal protein S14 (A0A1H6Q0M6), tropomyosin (YALIOF27049p) requisite for the cell fission and transport, triose phosphate isomerase (YALIOF05214p) involved in glycolysis, and the TCA enzyme of malate dehydrogenase (YALI0D16753p) (Figure 4). Under alkaline stress, the changes in the proteomic profile are restricted due to the key cell demands, namely, on the one hand, to reduce the damage by ROS, performed either through the regulation of cytochrome-c- oxidase using subunits IV and VI [43] or through switching of the metabolism to glycolysis and lipid $\beta$-oxidation. VDAC plays the key role in this process [44]. On the other hand, the process of the protein quality control, during which de novo synthesized proteins are checked at different levels of structural organization, and those with any errors should be destructed, is of great importance. This process helps the yeast to resist the replicative aging under unfavorable conditions [45].

Under heat stress, four original proteins were found, namely formate dehydrogenase (as two different fragments YALI0B22506p and the complete protein of CPAR2_203450), fructose biphosphate aldolase (CPAR2_401230), disulfide oxidoreductase (CPAR2_106080), and cofilin (YALI085). Formate dehydrogenase oxidizes formate to $\mathrm{CO}_{2}$, simultaneously reducing $\mathrm{NAD}^{+}$to NADH. The significance of the process in the protection of the cell against oxidative stress has been shown for some yeasts and plants, recently [45]. Disulfide oxidoreductase and an increment in glycolysis importance can also reduce the deleterious action of the ROS. HSPs of $70 \mathrm{kDa}$ perform numerous functions in response to stress, protecting the proteins from any damaging impacts (folding, disaggregation, and degradation of injured proteins).

Under heat and alkaline stress, common $70 \mathrm{kDa}$ HSPs from the SSA4 family were revealed. It is noteworthy that under alkaline stress, the YALI0D08184p protein was detected, while under heat stress, the YALI0D22352p and YALIOE35046p fragments were detected. Moreover, under both types of stress, there were some uncharacterized proteins, namely YALI0D00451p, YALI0F08327p, and YALI0A10747p under alkaline stress; and CPAR2_802980 under heat stress.

Under combined stress, we detected four original proteins. Firstly, there were CPCR1 (fragment) and CPAR2_502580 carbonyl reductases. Carbonyl reductases are known to be involved in the detoxification of cytotoxic products of lipid peroxidation [46,47]. ATP synthase subunit 5 CPAR2_503440, which contains SBDS-domain protein CPAR2_406210 involved in the ribosomes genesis, and a fragment of pyruvate dehydrogenase CPAR2_402950, were other original proteins for the combined stress.

The $\alpha-1$ elongation factor of the cytosolic GTPase was the only common protein for heat and combined stress. Moreover, under heat stress, it was the Q0ZIC1_CANPA protein, while under combined stress, it was the CPAR2_207060 protein fragment. We detected no common proteins for the alkaline and combined stresses. Of note, SSA4, revealed under both thermal and alkaline stress, was not detected under the conditions of combined stress. Two proteins, namely glyceraldehyde-3-phosphate dehydrogenase (YALI0C06369p in the normal and alkaline conditions and CPAR2_808670 under combined stress), as well as nucleoside-diphosphate kinase (YALI0F09229p in the normal and alkaline $\mathrm{pH}$ conditions, and fragment CPAR2-101390) were common for the normal, alkaline and combined stress 
conditions. HSPs of $70 \mathrm{kDa}$, namely CPAR2_700380, detected under combined stress, and the YALI0F25289p fragment, detected under normal conditions, were the common proteins for the normal and the combined stress conditions. Thioredoxin was the common protein revealed under normal conditions and both types of stress. CPAR2_200490 was detected under heat stress and YALI0F01496 $\mathrm{p}$ was detected at normal and alkaline $\mathrm{pH}$ values. Moreover, the level of the latter protein decreased under alkaline stress.

Finally, $\mathrm{Cu} / \mathrm{Zn}-\mathrm{SOD}$ was detected under all the conditions studied. Under normal conditions and at an alkaline $\mathrm{pH}$, YALIOE12133p was the common protein, and its level increased at pH 9.0. Under heat stress, we detected CPAR2_500390, while under combined stress, it was identified only as a fragment. Thus, $\mathrm{Cu} / \mathrm{Zn}-\mathrm{SOD}$, thioredoxin, and various $70 \mathrm{kDa} \mathrm{HSP}$ chaperones proved to be the most versatile cytoprotective proteins. The regulation of cytochrome c oxidase and an increase in the VDAC amount were the adaptation factors original for the alkaline stress. Upon adapting to the heat shock, formate dehydrogenase was an exclusive protein, while under the combined stress conditions, it was carbonyl reductase.

\section{Concluding Remarks}

The results show that the proteomic profile reflects the metabolic readjustment under various growth conditions (Scheme 1). At an extreme $\mathrm{pH}$, pathways shift towards the oxidative metabolism of glyceraldehyde-3-phosphate into pyruvate in the mitochondria, its implication in the Krebs cycle followed by forming citrate, its transport into the cytosol, and inclusion into lipid biosynthesis (Scheme 1). At an increased temperature, glycerol is metabolized, forming glucose in the cytoplasm with a concurrent synthesis of trehalose (Scheme 1).

Therefore, the analysis of the protein composition of the $Y$. lipolytica yeast under different conditions revealed some regularity in the response to various stresses. We observed a special impact of alkaline $\mathrm{pH}$ and increased temperature on changing the proteomic profile. The changes in the mitochondria activity, which were displayed in inducing VDAC porin and malate dehydrogenase, played an essential role in the adaptation. The culture growth under combined stress caused the changes in the proteomics differed from those at either alkaline or heat stresses alone. Moreover, the readjustment of the protein (chaperones and carbonyl reductases) composition and amount occurred, which indicated the induction of catabolic processes related to scavenging damaged proteins and lipids under the conditions of combined stress. The data analysis suggests that adaptation to the combined stress should include significant readjustment of the carbohydrates and lipid metabolism, as well as the cell's protection against lipid peroxidation products and protein destruction. The combination of chronic alkaline and heat stress ( $\mathrm{pH}$ 9.0, $38^{\circ} \mathrm{C}$ ) leads to the cross-adaptation expressed in "switching" usual metabolism over the adaptation to the most damaging stress factor, i.e., the increased temperature. 


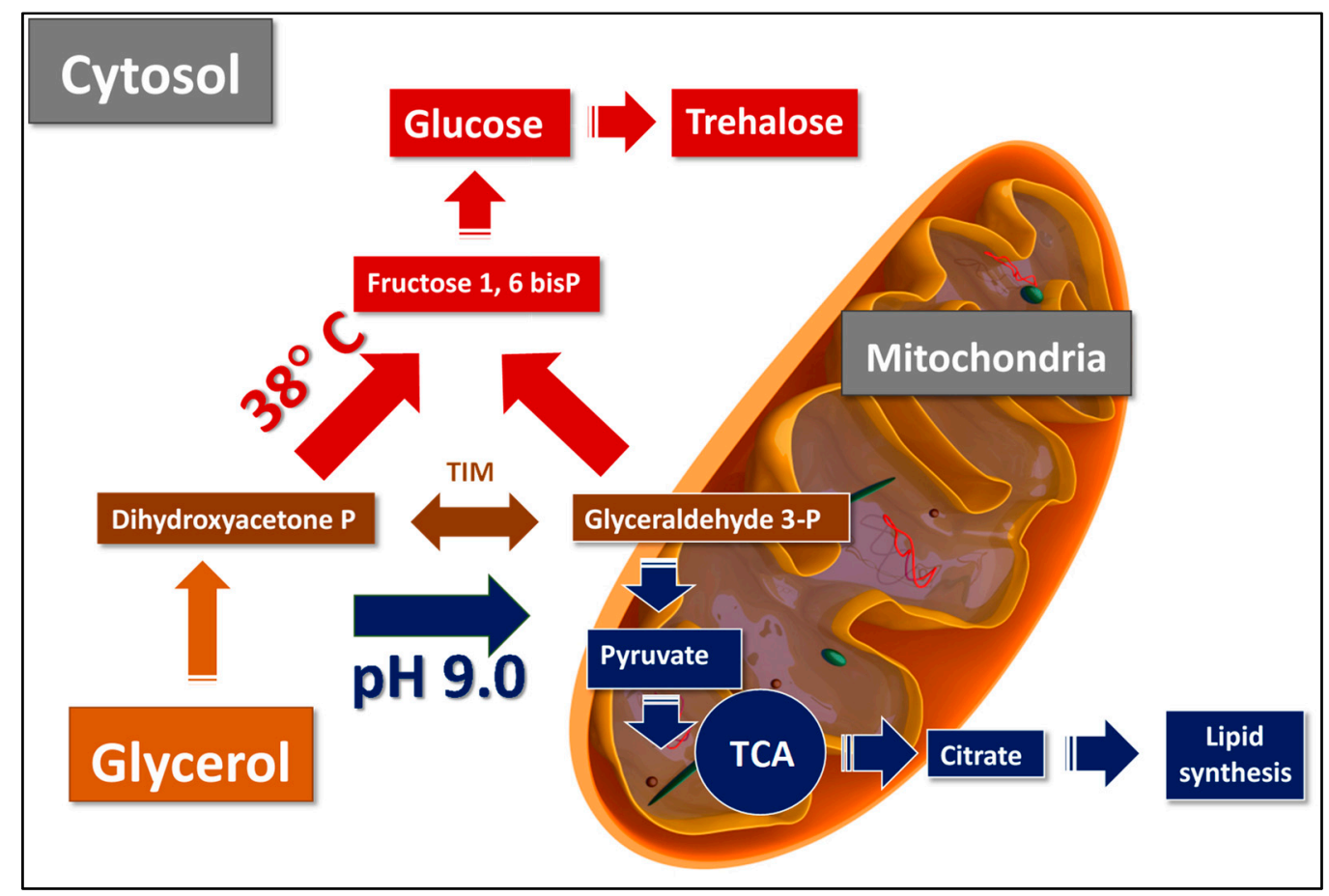

Scheme 1. The hypothetical pathways of glycerol utilization in Y. lipolytica under heat and $\mathrm{pH}$ stress. At an increased temperature, glycerol is metabolized, forming glucose in the cytoplasm in the reactions of gluconeogenesis and the subsequent synthesis of trehalose. At extreme $\mathrm{pH}$, pathways shift towards the oxidative metabolism of glyceraldehyde-3phosphate into pyruvate in the mitochondria, its implication in the Krebs cycle followed by forming citrate, its transport into the cytosol, and inclusion into lipid biosynthesis. According to Workman et al. [25], glyceraldehyde-3-phosphate can be converted in the mitochondria to glyceraldehyde-3-phosphate shuttle, being the one primarily used by Y. lipolytica due to the high oxygen requirement for biomass formation accompanying glycerol utilization. TIM-triose phosphate isomerase; TCA-tricarboxilic cycle.

Thus, modeling the cultivation conditions of the Y. lipolytica yeast may be used for the streamlined synthesis of the lipid or carbohydrate metabolites for industrial purposes.

Supplementary Materials: The following are available online at https:/ / www.mdpi.com/article/ 10.3390/microorganisms9122619/s1, Figure S1: QR-code of the availability to the complete list of the proteins; Figure S2. The number of the identified proteins ( $x$-axis) involved in different metabolic pathways under the normal conditions; Figure S3. The number of the identified proteins $(x$-axis) involved in different metabolic pathways at the alkaline stress; Figure S4. The number of the identified original proteins ( $x$-axis) involved in different metabolic pathways at the heat; Table S1: The full protein list; Table S2: linked to Figure 4; Table S3: linked to Figure 5.

Author Contributions: Conceptualization, Y.I.D. and V.Y.S.; methodology, L.I.K. and M.A.K.; software, V.Y.S. and N.N.G.; validation, E.P.I. and M.A.D.; formal analysis, L.I.K. and M.A.K.; investigation, V.Y.S. and L.I.K.; resources, Y.I.D. and L.I.K.; data curation, L.I.K.; writing-original draft preparation, Y.I.D., N.N.G. and V.Y.S.; writing-review and editing, E.P.I. and Y.I.D.; visualization, E.P.I.; supervision, Y.I.D.; project administration, Y.I.D.; funding acquisition, Y.I.D. All authors have read and agreed to the published version of the manuscript.

Funding: This study was supported by the State Assignment 0104-2019-0024 to Research Center of Biotechnology RAS.

Conflicts of Interest: The authors declare no conflict of interest. 


\section{References}

1. Danilova, O.A.; Ianutsevich, E.A.; Bondarenko, S.A.; Georgieva, M.L.; Vikchizhanina, D.A.; Groza, N.V.; Bilanenko, E.N.; Tereshina, V.M. Osmolytes and membrane lipids in the adaptation of micromycete Emericellopsis alkalina to ambient pH and sodium chloride. Fungal Biol. 2020, 124, 884-891. [CrossRef]

2. Zvyagilskaya, R.A.; Parkhomenko, O.A.; Gordeeva, A.V.; Deryabina, Y.I.; Persson, B.L. Bioenergetics of Yarrowia lipolytica Cells Grown at Alkaline Conditions. Biosci. Rep. 2004, 24, 117-125. [CrossRef]

3. Egermeier, M.; Russmayer, H.; Sauer, M.; Marx, H. Metabolic Flexibility of Yarrowia lipolytica Growing on Glycerol. Front. Microbiol. 2017, 8, 49. [CrossRef]

4. Sekova, V.Y.; Dergacheva, D.I.; Isakova, E.P.; Gessler, N.N.; Tereshina, V.M.; Deryabina, Y.I. Soluble Sugar and Lipid Readjustments in the Yarrowia lipolytica Yeast at Various Temperatures and pH. Metabolites 2019, 9, 307. [CrossRef] [PubMed]

5. Qiu, X.; Zhang, J.; Zhou, J.; Fang, Z.; Zhu, Z.; Li, J.; Du, G. Stress tolerance phenotype of industrial yeast: Industrial cases, cellular changes, and improvement strategies. Appl. Microbiol. Biotechnol. 2019, 103, 6449-6462. [CrossRef] [PubMed]

6. Święciło, A. Cross-stress resistance in Saccharomyces cerevisiae yeast-New insight into an old phenomenon. Cell Stress Chaperon. 2016, 21, 187-200. [CrossRef] [PubMed]

7. Guo, H.; Wan, H.; Chen, H.; Fang, F.; Liu, S.; Zhou, J. Proteomic analysis of the response of $\alpha$-ketoglutarate-producer Yarrowia lipolytica WSH-Z06 to environmental pH stimuli. Appl. Microbiol. Biotechnol. 2016, 100, 8829-8841. [CrossRef]

8. Epova, E.; Guseva, M.; Kovalyov, L.; Isakova, E.; Deryabina, I.Y.; Belyakova, A.; Zylkova, M.; Shevelev, M.Z.A.A. Identification of Proteins Involved in $\mathrm{pH}$ Adaptation in Extremophile Yeast Yarrowia lipolytica. In Proteomic Applications in Biology; IntechOpen: Rijeka, Croatia, 2012; pp. 209-224.

9. Yang, L.B.; Dai, X.M.; Zheng, Z.Y.; Zhu, L.; Zhan, X.B.; Lin, C.C. Proteomic Analysis of Erythritol-Producing Yarrowia lipolytica from Glycerol in Response to Osmotic Pressure. Microbiol. Biotechnol. 2015, 25, 1056-1069. [CrossRef]

10. Arinbasarova, A.Y.; Biryukova, E.N.; Medentsev, A.G. Antistress Systems of the Yeast Yarrowia lipolitica (Review). Prikl. Biokhim. Mikrobiol. 2015, 51, 122-131. [CrossRef]

11. Kovalyov, L.I.; Shishkin, S.S.; Efimochkin, A.S.; Kovalyova, M.A.; Ershova, E.S.; Egorov, T.A.; Musalyamov, A.K. The major protein expression profile and two-dimensional protein database of human heart. Electrophoresis 1995, 16, 1160-1169. [CrossRef]

12. Kovalyova, M.A.; Kovalyov, L.I.; Serebryakova, M.V. Age-Related Changes in Albumin and Actin of Human Myo-cardium. Biochemistry 2008, 2, 160-165.

13. Kovalyova, M.A.; Kovalyov, L.I.; Toropygin, I.Y.; Shigeev, S.V.; Ivanov, A.V.; Shishkin, S.S. Proteomic analysis of human skeletal muscle (m. vastus lateralis) proteins: Identification of 89 gene expression products. Biochemistry 2009, 74, 1239-1252. [CrossRef] [PubMed]

14. Govorun, V.M.; Moshkovskii, S.A.; Tikhonova, O.V.; Goufman, E.I.; Serebryakova, M.V.; Momynaliev, K.T.; Lokhov, P.G.; Khryapova, E.V.; Kudryavtseva, L.V.; Smirnova, O.V. Comparative Analysis of Proteome Maps of Helicobacter pylori Clinical Isolates. Biochemistry 2003, 68, 42-49. [CrossRef]

15. Kovalyova, M.A.; Kovalyov, L.I.; Hudaidatov, A.I.; Efimochkin, A.S.; Shishkin, S.S. Compatrative analysis of protein composition of human skeleton and cardiac muscle by 2D electrophoresis. Biochemistry 1994, 59, 675-681.

16. Laptev, A.V.; Shishkin, S.S.; Egorov, T.A.; Kovalyov, L.I.; Tsvetkova, M.N.; Galuk, M.A.; Musalyamov, A.H.; Efimochkin, A.S. Search for new products of gene expression in human cardiav muscle; micro-sequencing of proteins after two-dimensional electrophoresis. Mol. Biol. 1994, 28, 52-58.

17. Osterman, L.A. Electrophoresis and ultracentrigugation. In Methods of the Investigation of Proteins and Nucleic Acids; Nauka: Moscow, Russia, 1981; pp. 56-58.

18. Vega, R.; Domínguez, A. Cell wall composition of the yeast and mycelial forms of Yarrowia lipolytica. Arch. Microbiol. 1986, 144, 124-130. [CrossRef]

19. Free, S.J. Fungal Cell Wall Organization and Biosynthesis. Adv. Genet. 2013, 81, 33-82. [CrossRef] [PubMed]

20. Teparić, R.; Lozančić, M.; Mrša, V. Evolutionary Overview of Molecular Interactions and Enzymatic Activities in the Yeast Cell Walls. Int. J. Mol. Sci. 2020, 21, 8996. [CrossRef]

21. She, X.; Calderone, R.; Kruppa, M.; Lowman, D.; Williams, D.; Zhang, L.; Gao, Y.; Khamooshi, K.; Liu, W.; Li, D. Cell Wall N-Linked Mannoprotein Biosynthesis Requires Goa1p, a Putative Regulator of Mitochondrial Complex I in Candida albicans. PLoS ONE 2016, 11, e0147175. [CrossRef] [PubMed]

22. Reading, D.S.; Hallberg, R.L.; Myers, A. Characterization of the yeast HSP60 gene coding for a mitochondrial assembly factor. Nat. Cell Biol. 1989, 337, 655-659. [CrossRef]

23. Horwich, A.L.; Fenton, W.A. Chaperonin-assisted protein folding: A chronologue. Q. Rev. Biophys. 2020, 53, e4. [CrossRef] [PubMed]

24. Seto, E.; Yoshida, M. Erasers of Histone Acetylation: The Histone Deacetylase Enzymes. Cold Spring Harb. Perspect. Biol. 2014, 6, a018713. [CrossRef] [PubMed]

25. Workman, M.; Holt, P.; Thykaer, J. Comparing cellular performance of Yarrowia lipolytica during growth on glucose and glycerol in submerged cultivations. AMB Express 2013, 3, 58. [CrossRef]

26. Endo, T.; Sakaue, H. Multifaceted roles of porin in mitochondrial protein and lipid transport. Biochem. Soc. Trans. 2019, 47, 1269-1277. [CrossRef]

27. Grevel, A.; Becker, T. Porins as helpers in mitochondrial protein translocation. Biol. Chem. 2019, 401, 699-708. [CrossRef] 
28. Sanyal, S.K.; Kanwar, P.; Fernandes, J.L.; Mahiwal, S.; Yadav, A.K.; Samtani, H.; Srivastava, A.K.; Suprasanna, P.; Pandey, G.K. Arabidopsis Mitochondrial Voltage-Dependent Anion Channels Are Involved in Maintaining Reactive Oxygen Species Homeostasis, Oxidative and Salt Stress Tolerance in Yeast. Front. Plant Sci. 2020, 11, 50. [CrossRef] [PubMed]

29. Shevade, A.; Strogolova, V.; Orlova, M.; Yeo, S.T.; Kuchin, S. Mitochondrial Voltage-Dependent Anion Channel Protein Por1 Positively Regulates the Nuclear Localization of Saccharomyces cerevisiae AMP-Activated Protein Kinase. mSphere 2018, 3, e00482-17. [CrossRef] [PubMed]

30. Miyata, N.; Fujii, S.; Kuge, O. Porin proteins have critical functions in mitochondrial phospholipid metabolism in yeast. J. Biol. Chem. 2018, 293, 17593-17605. [CrossRef]

31. Liszka, A.; Schimpf, R.; Zaruma, K.I.C.; Buhr, A.; Seidel, T.; Walter, S.; Knuesting, J.; Dreyer, A.; Dietz, K.-J.; Scheibe, R.; et al. Three cytosolic NAD-malate dehydrogenase isoforms of Arabidopsis thaliana: On the crossroad between energy fluxes and redox signaling. Biochem. J. 2020, 477, 3673-3693. [CrossRef]

32. Mettlen, M.; Chen, P.-H.; Srinivasan, S.; Danuser, G.; Schmid, S.L. Regulation of Clathrin-Mediated Endocytosis. Annu. Rev. Biochem. 2018, 87, 871-896. [CrossRef]

33. Shishkin, S.; Eremina, L.; Pashintseva, N.; Kovalev, L.; Kovaleva, M. Cofilin-1 and Other ADF/Cofilin Superfamily Members in Human Malignant Cells. Int. J. Mol. Sci. 2016, 18, 10. [CrossRef]

34. Wang, Q.; Yuan, W.; Yang, X.; Wang, Y.; Li, Y.; Qiao, H. Role of Cofilin in Alzheimer's Disease. Front. Cell Dev. Biol. 2020, 8, 584-589. [CrossRef]

35. Flores, C.-L.; Gancedo, C.; Petit, T. Disruption of Yarrowia lipolytica TPS1 Gene Encoding Trehalose-6-P Synthase Does Not Affect Growth in Glucose but Impairs Growth at High Temperature. PLoS ONE 2011, 6, e23695. [CrossRef]

36. Araiza-Olivera, D.; Sampedro, J.G.; Mújica, A.; Peña, A.; Uribe-Carvajal, S. The association of glycolytic enzymes from yeast confers resistance against inhibition by trehalose. FEMS Yeast Res. 2010, 10, 282-289. [CrossRef]

37. Jastrząb, A.; Skrzydlewska, E. Thioredoxin-dependent system. Application of inhibitors. J. Enzym. Inhib. Med. Chem. 2021, 36, 362-371. [CrossRef]

38. Tishkov, V.I.; Popov, V. Protein engineering of formate dehydrogenase. Biomol. Eng. 2006, 23, 89-110. [CrossRef] [PubMed]

39. Takacs, M.; Makhlynets, O.V.; Tolbert, P.L.; Korendovych, I.V. Secretion of functional formate dehydrogenase in Pichia pastoris. Protein Eng. Des. Sel. 2017, 30, 381-386. [CrossRef]

40. Jakoblinnert, A.; Bocola, M.; Bhattacharjee, M.; Steinsiek, S.; Bönitz-Dulat, M.; Schwaneberg, U.; Ansorge-Schumacher, M.B. Who's Who? Allocation of Carbonyl Reductase Isoenzymes from Candida parapsilosis by Combining Bio- and Computational Chemistry. ChemBioChem 2012, 13, 803-809. [CrossRef] [PubMed]

41. Dhoke, G.V.; Ensari, Y.; Davari, M.D.; Ruff, A.J.; Schwaneberg, U.; Bocola, M. What's My Substrate? Computational Function Assignment of Candida parapsilosis ADH5 by Genome Database Search, Virtual Screening, and QM/MM Calculations. J. Chem. Inf. Model. 2016, 56, 1313-1323. [CrossRef] [PubMed]

42. Nirody, J.A.; Budin, I.; Rangamani, P. ATP synthase: Evolution, energetics, and membrane interactions. J. Gen. Physiol. 2020, 152. [CrossRef]

43. Timón-Gómez, A.; Bartley-Dier, E.L.; Fontanesi, F.; Barrientos, A. HIGD-Driven Regulation of Cytochrome $c$ Oxidase Biogenesis and Function. Cells 2020, 9, 2620. [CrossRef] [PubMed]

44. De Pinto, V. Renaissance of VDAC: New Insights on a Protein Family at the Interface between Mitochondria and Cytosol. Biomology 2021, 11, 107. [CrossRef] [PubMed]

45. Yoshida, M.; Kato, S.; Fukuda, S.; Izawa, S. Acquired Resistance to Severe Ethanol Stress in Saccharomyces cerevisiae Protein Quality Control. Appl. Environ. Microbiol. 2021, 87, 02353-20. [CrossRef] [PubMed]

46. Rashid, M.A.; Haque, M.; Akbar, M. Detoxification of Carbonyl Compounds by Carbonyl Reductase in Neurodegeneration. Glutamate ATP Interface Metab. Signal. Brain 2016, 12, 355-365. [CrossRef]

47. Kwon, J.H.; Lee, J.; Kim, J.; Kirchner, V.A.; Jo, Y.H.; Miura, T.; Kim, N.; Song, G.-W.; Hwang, S.; Lee, S.-G.; et al. Upregulation of Carbonyl Reductase 1 by $\mathrm{Nrf}_{2}$ as a Potential Therapeutic Intervention for Ischemia/Reperfusion Injury during Liver Transplantation. Mol. Cells 2019, 42, 672-685. [CrossRef] 